\title{
Gelatin-Tannin Based Greener Binder Technology for Stone Shot and Stone Wool Materials: A Detailed Study
}

Thomas Hjelmgaard, ${ }^{* a}$ Josefine Øgaard Svendsen, ${ }^{a}$ Berthold Köhler, ${ }^{b}$ Paul Pawelzyk, ${ }^{b}$ Dorthe Lybye, ${ }^{a}$

Carina Michella Schmücker, ${ }^{a}$ Peter Reiter, ${ }^{b}$ Matthias Reihmann, ${ }^{b}$ Peter Anker Thorsen ${ }^{a}$

${ }^{a}$ ROCKWOOL International A/S, Hovedgaden 584, Entrance C, 2640 Hedehusene, Denmark

b GELITA AG, Uferstrasse 7, 69502 Eberbach, Germany.

* E-mail: thomas.hjelmgaard@rockwool.com

\section{CONTENTS}

$\begin{array}{ll}\text { Further details to Results and Discussion } & \text { S2 }\end{array}$

$\begin{array}{ll}\text { Variations in gelatins - viscosity parameter } & \text { S2 }\end{array}$

Variations in gelatins - mixtures of gelatins $\quad \mathrm{S} 3$

Variations in gelatins - contact angle studies $\quad$ S5

$\begin{array}{ll}\text { Further details to Experimental Section } & \text { S7 }\end{array}$

$\begin{array}{ll}\text { General experimental methods - details on gelatins } & \text { S7 }\end{array}$

$\begin{array}{ll}\text { General experimental methods - further details } & \text { S7 }\end{array}$

$\begin{array}{ll}\text { Manufacture of composite bars under argon } & \text { S8 }\end{array}$

$\begin{array}{ll}\text { Ageing treatment of composite bars } & \text { S9 }\end{array}$

Measurement of mechanical strengths of composite bars $\quad$ S9

$\begin{array}{ll}\text { Measurement of binder content in composite bars } & \text { S10 }\end{array}$

$\begin{array}{ll}\text { Measurement of water uptake in composite bars } & \text { S10 }\end{array}$

$\begin{array}{ll}\text { Films for contact angle measurements } & \text { S11 }\end{array}$

$\begin{array}{ll}\text { Further details on mixing of binder compositions } & \text { S12 }\end{array}$

$\begin{array}{ll}\text { Further detailed results for composite bars } & \text { S28 }\end{array}$

$\begin{array}{ll}\text { References } & \text { S48 }\end{array}$ 


\section{FURTHER DETAILS TO RESULTS AND DISCUSSION}

\section{Variations in gelatins - viscosity parameter}

In order to investigate the impact of the viscosity parameter of the gelatin component, a comparative study was carried out herein using the type A gelatin GA291v. This gelatin is characterized by a gel strength comparable to that of the type A gelatin GA305 (291 vs. 305 bloom) while the viscosity is significantly higher (5.5 vs. $3.9 \mathrm{mPa} \times \mathrm{s}$ for a $6.67 \%$ aq. solution at $60{ }^{\circ} \mathrm{C}$ ). An overview of the results obtained for bars produced with GA291v, GA305 and GA120 modified with $0-50 \% \mathrm{TC}$ in the presence of $\mathrm{NaOH}$ at $\mathrm{pH} 9$ is shown in Figure $\mathrm{S} 1$. The mechanical strengths and binder solubilities for the use of GA305 and GA120 were reported previously, ${ }^{(\mathrm{S} 1)}$ and are included for comparison.
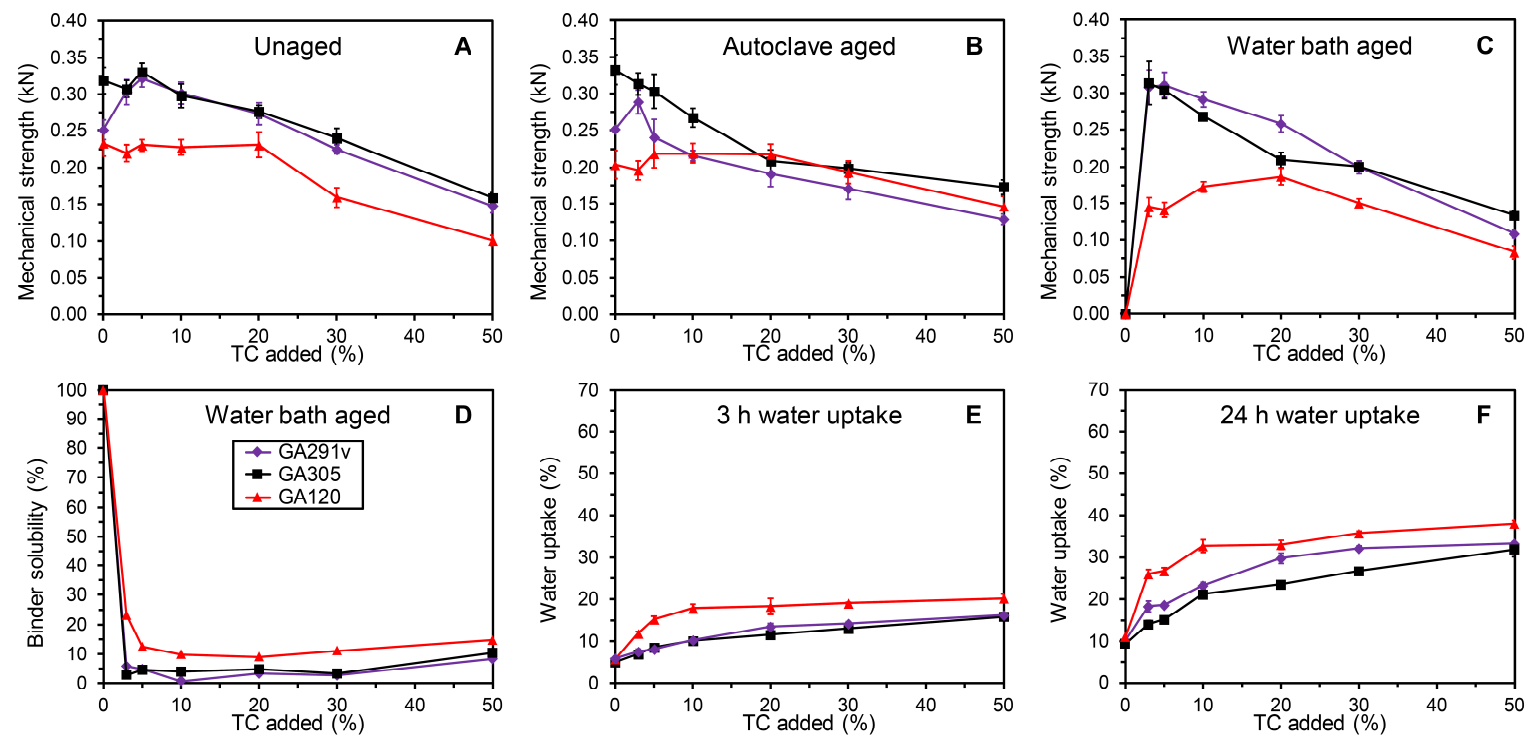

FIGURE S1. Overview of unaged and aged mechanical strength (A-C), binder solubility (D) and water uptake properties (E-F) of composite bars made from stone shots and GA291v ( $\bullet$, violet), GA305 ( $\mathbf{m}$, black), and GA120 $(\boldsymbol{\Delta}$, red) modified with $\mathrm{TC}$ in the presence of $\mathrm{NaOH}$ at $\mathrm{pH}$ 9. Data for the mechanical strengths and water uptakes are expressed as mean \pm standard error $(n=5$ and $n=3$, respectively). 
When comparing the results obtained for GA291v and GA305, the viscosity generally only had a minor impact on the unaged mechanical strengths of the bars (Fig. S1A). After subjection to autoclave ageing, however, the mechanical strengths of the bars produced with the higher viscosity GA291v were generally somewhat lower than for the analogous bars made with GA305 (Fig. S1B). Interestingly, though, the opposite pattern was obtained after water bath ageing where the bars produced with GA291v generally performed at least as well as the bars produced with GA305 (Fig. S1C). This was also reflected in a slightly lower general solubility of the binder series based on GA291v when compared to GA305 (Fig. S1D). After 3 h, only small differences in water uptake properties were observed between bars made with GA291v and GA305 (Fig. S1E). However, after 24 h, the water uptakes of bars made with GA291v were generally higher than the water uptakes of bars made with GA305 (Fig. S1F). Overall, these results show that the viscosity parameter has a significant impact on the resulting binder properties and this parameter should therefore be considered when developing these gelatinbased binder systems.

\section{Variations in gelatins - mixtures of gelatins}

An important effect of increasing the strength and viscosity of the gelatins is that the setting time of the resulting binder system decreases accordingly. While a short setting time may be useful in some applications, a longer setting time may be desirable in others. To this end, adding a small amount of high strength gelatins to lower strength gelatins may result in significant strength effects while the setting time remains unchanged. The effect of substituting $10 \%$ of GA120 with GA305 (high strength type A gelatin) or GB278vs (high strength type B gelatin) was therefore investigated. An overview of the results obtained for bars produced with GA120/GA305 90:10, GA120/GB278vs 90:10, GA305 and GA120 modified with 0-20\% TC 
in the presence of $\mathrm{NaOH}$ at $\mathrm{pH} 9$ is shown in Figure $\mathrm{S} 2$. The mechanical strengths and binder solubilities for use of for GA305 and GA120 were reported previously, ${ }^{(\mathrm{S} 1)}$ and are included for comparison.
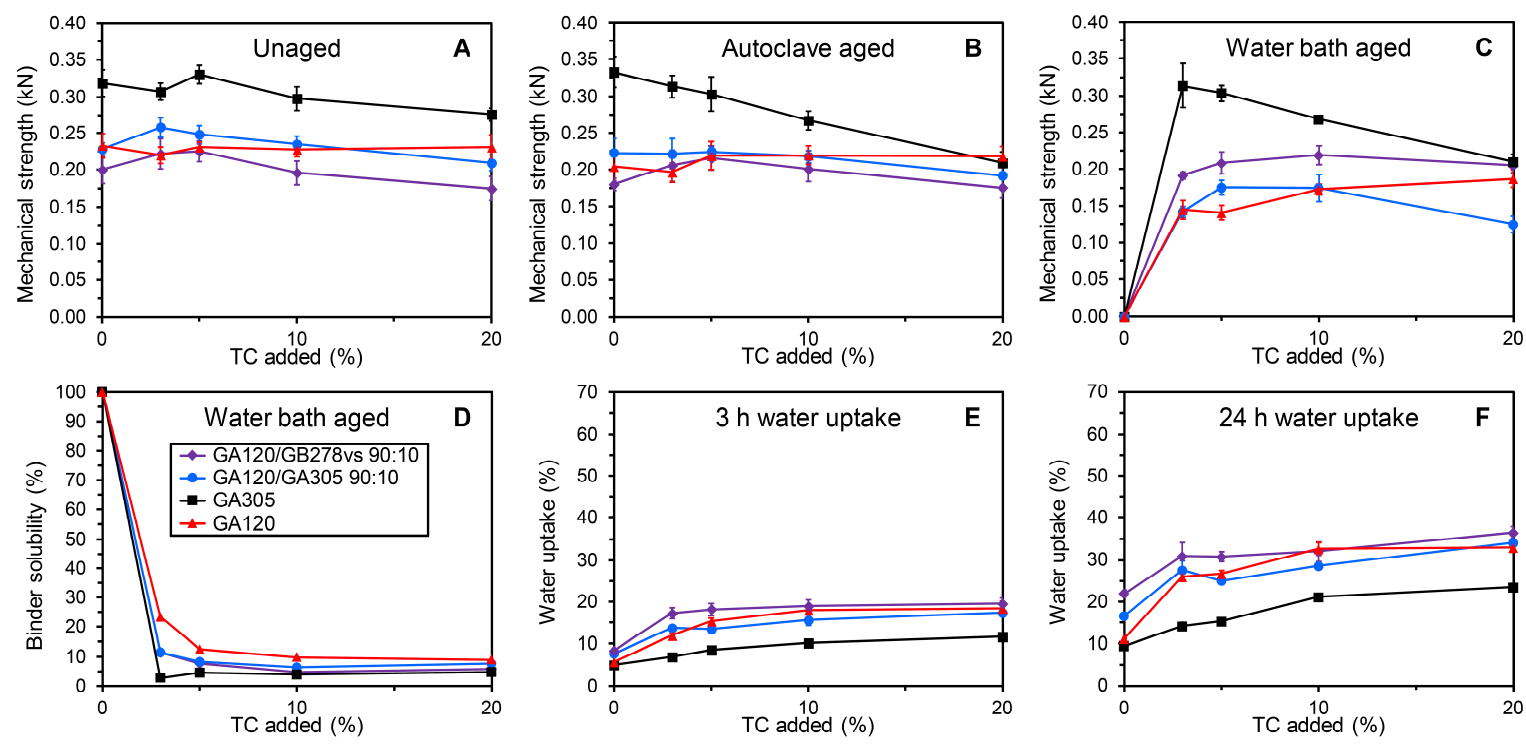

FIGURE S2. Overview of unaged and aged mechanical strength (A-C), binder solubility (D) and water uptake properties (E-F) of composite bars made from stone shots and GA120/GB278vs 90:10 (», violet), GA120/GA305 90:10 (•, blue), GA305 ( $\bullet$, black), and GA120 ( $\boldsymbol{\Lambda}$, red) modified with TC in the presence of $\mathrm{NaOH}$ at pH 9. Data for the mechanical strengths and water uptakes are expressed as mean \pm standard error $(n=5$ and $n=3$, respectively).

As expected, the substitution of $10 \%$ of GA120 with the higher strength gelatins GA305 or GA278vs resulted in no apparent changes to the binder setting time during manufacture of the composite bars compared to the use of GA120 as the sole gelatin component. The most significant strength increase compared to use of GA120 only was observed for substitution with $10 \%$ GB278vs after water bath ageing (Fig. S2C). While the inclusion of $10 \%$ GB278vs thus provided better strength results after water bath ageing than inclusion of 10\% GA305 (Fig. S2C), substitution with $10 \%$ GA305 appeared to yield the best results of the two in terms of 
unaged and autoclave aged strengths, providing some strength improvements at low tannin content range $(2.5-5 \%$, Fig. S2A-B). Interestingly, the inclusion of the two high strength gelatins had a significant impact on the binder solubility which generally decreased to levels closer to those obtained for the use of GA305 or GB278vs only (Fig. S2D). As could be expected, the water uptakes generally increased slightly as a result of substitution with $10 \%$ of the type B gelatin GB278vs, especially at low tannin contents (Fig. S2E-F). Only minor effects were observed as a result of substitution with $10 \%$ of the type A gelatin GA305 (Fig. S2E-F). Overall, these results demonstrated that significant effects on the properties of the gelatin-based binder systems may be obtained by mixing gelatins with different characteristics such as gel strength and type.

\section{Variations in gelatins - contact angle studies}

In order to study the wettability of the gelatine-based binder systems both in the presence and in the absence of a stone surface, films were produced from GA120 and GB122 modified with $0 \%, 10 \%$, and $50 \% \mathrm{TC}$ in the presence of $\mathrm{NaOH}$ at $\mathrm{pH} 9$. The resulting contact angles measured 10 seconds after application of a droplet of water are listed in Table S1 and illustrated in Figure S3. 


\begin{tabular}{lcccccc}
\hline Entry & $\mathbf{1}$ & $\mathbf{2}$ & $\mathbf{3}$ & $\mathbf{4}$ & $\mathbf{5}$ & $\mathbf{6}$ \\
\hline Binder composition & & & & & & \\
GA120 & 100 & 100 & 100 & - & - & - \\
GB122 & - & - & - & 100 & 100 & 100 \\
TC (\%-wt. of gelatin) & 0 & 10 & 50 & 0 & 10 & 50 \\
\hline Film results & & & & & & \\
Avg. contact angle $\left({ }^{\circ}, \mathrm{n}=3\right)$ & 54.4 & 47.5 & 46.5 & 52.7 & 46.1 & 45.6 \\
Standard error $(\%)$ & 2.2 & 1.1 & 3.7 & 2.5 & 1.1 & 0.9 \\
\hline
\end{tabular}

TABLE S1. Results for contact angle measurements.

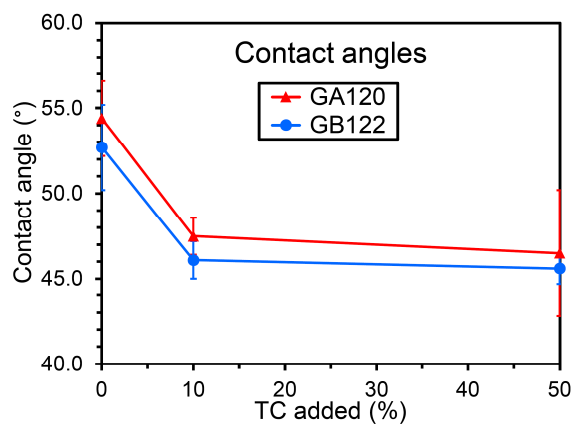

FIGURE S3. Contact angles measured for films made from GA120 ( $\boldsymbol{\Delta}$, red $)$ and GB122 $(\bullet$, blue $)$, modified with $\mathrm{TC}$ and $\mathrm{NaOH}$ at $\mathrm{pH} 9$.

The measurements on films confirmed the results obtained from the water uptake measurements on composite bars produced with the analogous binder systems. Thus, the gelatine-based binder systems generally became more hydrophilic with increasing amounts of TC added and the most significant increase in hydrophilicity was observed in the $0-10 \%$ TC range. Furthermore, the binder compositions comprising the type B gelatin GB122 were more hydrophilic than the corresponding binder compositions based on the type A gelatin GA120. 


\section{FURTHER DETAILS TO EXPERIMENTAL SECTION}

\section{General experimental methods - details on gelatins}

Table S2 summarizes the properties of the gelatins used herein.

\begin{tabular}{cccccccc}
\hline Gelatin & $\begin{array}{c}\text { Commercial } \\
\text { name }\end{array}$ & Type & Bloom & $\begin{array}{c}\text { Viscosity } \\
(\mathrm{mPa} \times \mathrm{s} \text { at } \\
\left(6.67 \% / 60^{\circ} \mathrm{C}\right)\end{array}$ & $\begin{array}{c}\text { Loss on } \\
\text { drying } \\
(\%)\end{array}$ & $\begin{array}{c}\mathbf{p H} \\
(\mathrm{at} 6.67 \% / \\
\left.60{ }^{\circ} \mathrm{C}\right)\end{array}$ & $\begin{array}{c}\text { Conductivity } \\
(\mu \mathrm{S} / \mathrm{cm} \text { at } \\
\left.1.00 \% / 30^{\circ} \mathrm{C}\right)\end{array}$ \\
\hline GA78 & IMAGEL RL & A (porcine) & 78 & 1.67 & 11.8 & 4.92 & - \\
GA120 & IMAGEL LA & A (porcine) & 120 & 2.06 & 11.6 & 5.08 & - \\
GA180 & IMAGEL RA & A (porcine) & 180 & 3.00 & 11.9 & 5.13 & - \\
GA305 & IMAGEL AP & A (porcine) & 305 & 3.90 & 10.8 & 5.31 & 155 \\
GA291v & IMAGEL HP & A (porcine) & 291 & 5.53 & 10.3 & 5.58 & 156 \\
GB122 & IMAGEL LB & B (bovine) & 122 & 2.31 & 11.9 & 5.32 & 61 \\
GB267 & IMAGEL DP & B (bovine) & 267 & 2.89 & 9.6 & 5.46 & 63 \\
GB278vs & IMAGEL SI & B (bovine) & 278 & 4.41 & 10.6 & 5.08 & 10 \\
\hline
\end{tabular}

TABLE S2. Properties of gelatins.

\section{General experimental methods - further details}

Measurements of $\mathrm{pH}$ were performed using a Mettler Toledo SevenCompactTM S220 pH meter equipped with a Mettler Toledo InLab Expert Pro-ISM pH electrode and temperature probe. Contact angle measurements were conducted with a DataPhysics OCA $15+$ with en electronic syringe module and a film support rig. Three-point bending tests of composite bars were recorded on a Bent Tram SUT 3000/520 test machine (test speed: $10.0 \mathrm{~mm} / \mathrm{min}$; rupture level: $50 \mathrm{~N}$; nominal strength: $30 \mathrm{~N} / \mathrm{mm}^{2}$; support distance: $40 \mathrm{~mm}$; max deflection $20 \mathrm{~mm}$; nominal E-modulus $10000 \mathrm{~N} / \mathrm{mm}^{2}$ ). The bars were placed with the "top face" up (i.e. the face with the dimensions length $=5.6 \mathrm{~cm}$, width $=2.5 \mathrm{~cm}$ ) in the machine. New tin foil containers 
for use in measurement of binder contents of composite bars were heat-treated at $590{ }^{\circ} \mathrm{C}$ for 15 minutes prior to use to remove all organics.

\section{Manufacture of composite bars under argon}

The required reagents (GA120, TC and stone shots) were weighed off in the appropriately sized containers with magnetic stirring bars when relevant. These containers as well as further required equipment (magnetic stirrer, empty water bath, weight, bar form, spatulas and pipettes) were then placed in a purpose-built glove box $(60 \times 50 \times 40 \mathrm{~cm}$ width $/$ depth $/$ height $)$. Argon was bubbled through appropriately sized containers containing the required aqueous solutions $(1 \mathrm{M} \mathrm{NaOH}$ as well as deionized water) for $30-45$ mins. The containers were then closed tight and were also placed in the glove box. The glove box was then sealed tight except for a small $4 \mathrm{~mm}$ diameter exit hole in the top lid of the box. From then on, the glove box was kept under a constant argon stream. The argon stream was set to a high rate during the first few hours as well as when working in the box and for an hour after working in the box. At all other times the argon stream was set to a slow rate (so that a weak argon stream exiting the top lid hole could continuously be detected). Argon was passed through the glove box for a day during which time the different solid components (GA120, TC and stone shots) were stirred gently with plastic spatulas a few times. A sensitive $\mathrm{CO}_{2}$ measurement equipment placed inside the box indicated $\mathrm{CO}_{2}$ levels below the measurement limits. Water was then added to the water bath and the heating was turned on. Once the water bath had reached $50{ }^{\circ} \mathrm{C}$, the reagent solutions were prepared. After stirring for $30 \mathrm{~min}$, the finalized binder solution was prepared and 20 composite bars were produced as described in the article. The bars were carefully taken out of the containers after 1 day, turned upside down, and were then left for 2 days further to 
cure and dry completely. The bars were taken out of the box and a selection of the bars were subjected to water bath ageing after $2 \mathrm{~h}$.

To enable direct comparison with composite bars made in the presence of oxygen, a set of 20 bars were manufactured using a similar procedure, this time applying an air stream rather than an argon stream to the glove box. For convenience, the reagent solutions and finalized binder solutions were prepared outside the glove box. The binder solution was also added to the stone shots outside the glove box, but the rest of the procedure was then carried out inside the glove box as described above.

\section{Ageing treatment of composite bars}

Ageing treatment of composite bars was performed by subjecting the bars to autoclave treatment $\left(15 \mathrm{~min} / 120^{\circ} \mathrm{C} / 1.2 \mathrm{bar}\right)$ or water bath treatment $\left(3 \mathrm{~h} / 80^{\circ} \mathrm{C}\right)$ followed by cooling to room temperature and drying for 2-3 days.

\section{Measurement of mechanical strengths of composite bars}

The maximum load force required to break composite bars was recorded in a three-point bending test. For each data point, an average value was calculated on the basis of five bars that had been subjected to identical treatment. 


\section{Measurement of binder content in composite bars}

The binder content in the composite bars was measured in small tin foil containers by treatment at $590{ }^{\circ} \mathrm{C}$. The tin foil container was weighed and four bars (usually after being broken in the three-point bending test) were placed into the tin foil container. The ensemble was weighed and was then heat-treated at $590{ }^{\circ} \mathrm{C}$ for 30 minutes. After cooling to room temperature, the weight was recorded again and the binder content was calculated as percentage of the stone shots.

\section{Measurement of water uptake in composite bars}

The water uptake of the binders was measured by weighing three bars and then submerging the bars in water (approx. $250 \mathrm{~mL}$ ) in a beaker $(565 \mathrm{~mL}$, bottom $\varnothing=9.5 \mathrm{~cm}$; top $\varnothing=10.5 \mathrm{~cm}$; height $=7.5 \mathrm{~cm}$ ) for $3 \mathrm{~h}$ or $24 \mathrm{~h}$. The bars were placed next to each other on the bottom of the beaker with the "top face" down (i.e. the face with the dimensions length $=5.6 \mathrm{~cm}$, width $=2.5$ $\mathrm{cm})$. After the designated amount of time, the bars were lifted up one by one and allowed to drip off for one minute. The bars were held (gently) with the length side almost vertical so that the droplets would drip from a corner of the bar. The bars were then weighed and the water absorption was calculated as the percentage in weight increase of the start weight. For each data point, an average value was calculated on the basis of three bars that had been subjected to identical treatment. 


\section{Films for contact angle measurements}

$15 \%$-wt. binder solutions were obtained as described in the representative example in the article. The binder solutions were coated on top of polyethylene terephthalate films using an Erichsen COATMASTER 509 MC equipped with a film applicator set at $500 \mu \mathrm{m}$. The films were dried and conditioned for at least two weeks in a climatized room at $22{ }^{\circ} \mathrm{C}$ and $50 \% \mathrm{rh}$. The smooth bottom-side of the films was used for contact angle measurements. Measurement of contact angles was performed $10 \mathrm{sec}$ after application of the water droplet in order to avoid any potential influence from swelling. 


\section{FURTHER DETAILS ON MIXING OF BINDER COMPOSITIONS}

\section{Mixing of binder compositions comprising GA78, GA120, GA180, GA305 and GA291v modified with $\mathrm{TC}$ in the presence of $\mathrm{NaOH}$ at $\mathrm{pH} 9$}

Mixing details about binder compositions comprising GA78, GA120, GA180 and GA305 modified with $\mathrm{TC}$ in the presence of $\mathrm{NaOH}$ at $\mathrm{pH} 9$ have been published previously. ${ }^{(\mathrm{S} 1)}$ The mixing details of binder compositions comprising GA291v modified with TC in the presence of $\mathrm{NaOH}$ at $\mathrm{pH} 9$ are listed in Table S3. The binder compositions were mixed using procedures analogous to the representative examples described in the article, using $1.0 \mathrm{M} \mathrm{NaOH}$ for mixing of the TC mixture (deep red-brown).

\begin{tabular}{|c|c|c|c|c|c|c|c|}
\hline Entry & 1 & 2 & 3 & 4 & 5 & 6 & 7 \\
\hline \multicolumn{8}{|l|}{ Binder composition } \\
\hline GA291v & 100 & 100 & 100 & 100 & 100 & 100 & 100 \\
\hline TC (\%-wt. of gelatin) & 0 & 3 & 5 & 10 & 20 & 30 & 50 \\
\hline \multicolumn{8}{|l|}{ Mixing of binder composition } \\
\hline GA291v (g) & 12.00 & 12.00 & 12.00 & 12.00 & 12.00 & 11.00 & 9.50 \\
\hline Water (g) & 65.92 & 66.95 & 67.47 & 69.63 & 73.11 & 70.48 & 66.50 \\
\hline $1 \mathrm{M} \mathrm{NaOH}(\mathrm{g})$ & 2.95 & 2.95 & 2.95 & 2.95 & 2.95 & 2.70 & 2.30 \\
\hline $\mathrm{pH}$ & 9.1 & 9.1 & 9.2 & 9.2 & 9.1 & 9.3 & 9.2 \\
\hline TC mixture $(\mathrm{g})$ & 0 & 1.62 & 2.70 & 5.40 & 10.80 & 14.85 & 21.38 \\
\hline $\mathrm{pH}$ & - & 9.1 & 9.2 & 9.2 & 9.2 & 9.4 & 9.3 \\
\hline \multicolumn{8}{|l|}{ Calculated binder composition } \\
\hline Binder concentration (\%-wt. in water) & 15.0 & 15.0 & 15.0 & 15.0 & 15.0 & 15.0 & 15.0 \\
\hline GA291v (\%-wt. of gelatin/ & $100.0 /$ & $100.0 /$ & $100.0 /$ & $100.0 /$ & $100.0 /$ & $100.0 /$ & $100.0 /$ \\
\hline$\%$-wt. of all non-water components) & 99.1 & 95.8 & 93.8 & 89.1 & 80.9 & 74.1 & 63.4 \\
\hline TC (\%-wt. of gelatin/ & $0 /$ & $3.0 /$ & $5.0 /$ & $10.0 /$ & $20.0 \%$ & $30.0 /$ & $50.0 /$ \\
\hline$\%$-wt. of all non-water components) & 0 & 2.9 & 4.7 & 8.9 & 16.2 & 22.2 & 31.7 \\
\hline $\mathrm{NaOH}$ (\%-wt. of gelatin/ & $0.9 /$ & 1.41 & $1.6 /$ & 2.31 & $3.6 /$ & $5.0 \%$ & 7.71 \\
\hline$\%$-wt. of all non-water components) & 0.9 & 1.3 & 1.5 & 2.0 & 2.9 & 3.7 & 4.9 \\
\hline
\end{tabular}

TABLE S3. 
Mixing of binder compositions comprising GB122 modified with TC in the presence of $\mathrm{NaOH}$ at pH 9

The mixing details of binder compositions comprising GB122 modified with TC in the presence of $\mathrm{NaOH}$ at $\mathrm{pH} 9$ are listed in Table S4. The binder compositions were mixed using procedures analogous to the representative examples described in the article, using $1.0 \mathrm{M}$ $\mathrm{NaOH}$ for mixing of the TC mixture (deep red-brown).

\begin{tabular}{|c|c|c|c|c|c|c|c|}
\hline Entry & 1 & 2 & 3 & 4 & 5 & 6 & 7 \\
\hline \multicolumn{8}{|l|}{ Binder composition } \\
\hline GB122 & 100 & 100 & 100 & 100 & 100 & 100 & 100 \\
\hline TC (\%-wt. of gelatin) & 0 & 3 & 5 & 10 & 20 & 30 & 50 \\
\hline \multicolumn{8}{|l|}{ Mixing of binder composition } \\
\hline GB122 (g) & 12.00 & 12.00 & 12.00 & 12.00 & 12.00 & 11.00 & 9.50 \\
\hline Water (g) & 64.92 & 66.43 & 66.95 & 68.54 & 72.51 & 69.88 & 65.90 \\
\hline $1 \mathrm{M} \mathrm{NaOH}(\mathrm{g})$ & 3.85 & 3.85 & 3.85 & 3.85 & 3.85 & 3.73 & 3.14 \\
\hline $\mathrm{pH}$ & 9.2 & 9.1 & 9.0 & 9.0 & 9.0 & 8.8 & 9.0 \\
\hline TC mixture (g) & 0 & 1.62 & 2.70 & 5.40 & 10.80 & 14.85 & 21.38 \\
\hline $\mathrm{pH}$ & - & 9.0 & 9.0 & 9.0 & 9.0 & 9.0 & 9.1 \\
\hline \multicolumn{8}{|l|}{ Calculated binder composition } \\
\hline Binder concentration (\%-wt. in water) & 15.0 & 15.0 & 15.0 & 15.1 & 15.0 & 15.0 & 15.0 \\
\hline GB122 (\%-wt. of gelatin/ & $100.0 /$ & $100.0 /$ & $100.0 /$ & $100.0 /$ & $100.0 /$ & $100.0 /$ & $100.0 /$ \\
\hline$\%$-wt. of all non-water components) & 98.8 & 95.6 & 93.5 & 88.8 & 80.7 & 73.9 & 63.3 \\
\hline TC (\%-wt. of gelatin/ & $0 /$ & $3.0 /$ & $5.0 \%$ & $10.0 /$ & $20.0 /$ & $30.0 /$ & $50.0 /$ \\
\hline$\%$-wt. of all non-water components) & 0 & 2.9 & 4.7 & 8.9 & 16.1 & 22.2 & 31.6 \\
\hline $\mathrm{NaOH}(\%$-wt. of gelatin/ & $1.2 \%$ & $1.6 /$ & $1.9 /$ & $2.6 \%$ & $3.9 \%$ & $5.3 \%$ & $8.0 /$ \\
\hline$\%$-wt. of all non-water components) & 1.2 & 1.6 & 1.8 & 2.3 & 3.2 & 4.0 & 5.1 \\
\hline
\end{tabular}

TABLE S4. 
Mixing of binder compositions comprising GB267 modified with TC in the presence of $\mathrm{NaOH}$ at pH 9

The mixing details of binder compositions comprising GB267 modified with TC in the presence of $\mathrm{NaOH}$ at $\mathrm{pH} 9$ are listed in Table S5. The binder compositions were mixed using procedures analogous to the representative examples described in the article, using $1.0 \mathrm{M}$ $\mathrm{NaOH}$ for mixing of the TC mixture (deep red-brown).

\begin{tabular}{|c|c|c|c|c|c|c|c|}
\hline Entry & 1 & 2 & 3 & 4 & 5 & 6 & 7 \\
\hline \multicolumn{8}{|l|}{ Binder composition } \\
\hline GB267 & 100 & 100 & 100 & 100 & 100 & 100 & 100 \\
\hline TC (\%-wt. of gelatin) & 0 & 3 & 5 & 10 & 20 & 30 & 50 \\
\hline \multicolumn{8}{|l|}{ Mixing of binder composition } \\
\hline $\mathrm{GB} 267(\mathrm{~g})$ & 12.00 & 12.00 & 12.00 & 12.00 & 12.00 & 11.00 & 9.50 \\
\hline Water $(\mathrm{g})$ & 65.42 & 66.95 & 67.47 & 69.08 & 73.11 & 70.48 & 66.50 \\
\hline $1 \mathrm{M} \mathrm{NaOH}(\mathrm{g})$ & 3.30 & 3.30 & 3.30 & 3.30 & 3.30 & 3.00 & 2.85 \\
\hline $\mathrm{pH}$ & 9.1 & 9.1 & 9.0 & 9.1 & 9.0 & 9.0 & 9.0 \\
\hline TC mixture (g) & 0 & 1.62 & 2.70 & 5.40 & 10.80 & 14.85 & 21.38 \\
\hline $\mathrm{pH}$ & - & 9.0 & 9.0 & 9.1 & 9.1 & 9.0 & 9.1 \\
\hline \multicolumn{8}{|l|}{ Calculated binder composition } \\
\hline Binder concentration (\%-wt. in water) & 15.0 & 14.9 & 15.0 & 15.1 & 15.0 & 15.0 & 15.0 \\
\hline GB267 (\%-wt. of gelatin/ & $100.0 \%$ & $100.0 \%$ & $100.0 /$ & $100.0 \%$ & $100.0 \%$ & $100.0 \%$ & $100.0 \%$ \\
\hline$\%$-wt. of all non-water components) & 99.0 & 95.7 & 93.7 & 89.0 & 80.8 & 74.0 & 63.3 \\
\hline TC (\%-wt. of gelatin/ & $0 \%$ & $3.0 /$ & $5.0 \%$ & $10.0 /$ & $20.0 \%$ & $30.0 /$ & $50.0 \%$ \\
\hline$\%$-wt. of all non-water components) & 0 & 2.9 & 4.7 & 8.9 & 16.2 & 22.2 & 31.7 \\
\hline $\mathrm{NaOH}(\%$-wt. of gelatin/ & $1.1 \%$ & $1.5 \%$ & 1.71 & $2.47^{\circ}$ & $3.8 \%$ & $5.1 \%$ & $7.9 /$ \\
\hline$\%$-wt. of all non-water components) & 1.0 & 1.4 & 1.6 & 2.1 & 3.0 & 3.8 & 5.0 \\
\hline
\end{tabular}

TABLE S5. 


\section{Mixing of binder compositions comprising GB278vs modified with TC in the presence of $\mathrm{NaOH}$ at pH 9}

The mixing details of binder compositions comprising GB278vs modified with TC in the presence of $\mathrm{NaOH}$ at $\mathrm{pH} 9$ are listed in Table S6. The binder compositions were mixed using procedures analogous to the representative examples described in the article, using $1.0 \mathrm{M}$ $\mathrm{NaOH}$ for mixing of the TC mixture (deep red-brown).

\begin{tabular}{|c|c|c|c|c|c|c|c|}
\hline Entry & 1 & 2 & 3 & 4 & 5 & 6 & 7 \\
\hline \multicolumn{8}{|l|}{ Binder composition } \\
\hline GB278vs & 100 & 100 & 100 & 100 & 100 & 100 & 100 \\
\hline TC (\%-wt. of gelatin) & 0 & 3 & 5 & 10 & 20 & 30 & 50 \\
\hline \multicolumn{8}{|l|}{ Mixing of binder composition } \\
\hline GB278vs (g) & 12.00 & 12.00 & 12.00 & 12.00 & 12.00 & 11.00 & 9.50 \\
\hline Water $(\mathrm{g})$ & 64.43 & 65.92 & 66.43 & 68.54 & 71.92 & 69.29 & 65.90 \\
\hline $1 \mathrm{M} \mathrm{NaOH}(\mathrm{g})$ & 4.55 & 4.55 & 4.55 & 4.55 & 4.55 & 4.17 & 3.60 \\
\hline $\mathrm{pH}$ & 9.1 & 9.3 & 9.2 & 9.2 & 9.1 & 9.3 & 9.1 \\
\hline TC mixture $(\mathrm{g})$ & 0 & 1.62 & 2.70 & 5.40 & 10.80 & 14.85 & 21.38 \\
\hline $\mathrm{pH}$ & - & 9.2 & 9.2 & 9.2 & 9.1 & 9.2 & 9.1 \\
\hline \multicolumn{8}{|l|}{ Calculated binder composition } \\
\hline Binder concentration ( $\%$-wt. in water) & 15.0 & 15.0 & 15.0 & 15.1 & 15.0 & 15.0 & 15.0 \\
\hline GB278vs (\%-wt. of gelatin/ & $100.0 /$ & $100.0 /$ & $100.0 /$ & $100.0 /$ & $100.0 /$ & $100.0 /$ & $100.0 /$ \\
\hline$\%$-wt. of all non-water components) & 98.6 & 95.4 & 93.3 & 88.6 & 80.5 & 73.8 & 63.2 \\
\hline TC (\%-wt. of gelatin/ & $0 /$ & $3.0 /$ & $5.0 /$ & $10.0 /$ & $20.0 /$ & $30.0 /$ & $50.0 /$ \\
\hline$\%$-wt. of all non-water components) & 0 & 2.9 & 4.7 & 8.9 & 16.1 & 22.1 & 31.6 \\
\hline $\mathrm{NaOH}(\%-w t$. of gelatin/ & $1.5 /$ & $1.9 /$ & $2.1 /$ & $2.8 /$ & $4.2 \%$ & 5.5 & $8.2 \%$ \\
\hline$\%$-wt. of all non-water components) & 1.4 & 1.8 & 2.0 & 2.5 & 3.3 & 4.1 & 5.2 \\
\hline
\end{tabular}

TABLE S6. 


\section{Mixing of binder compositions comprising GA120/GA305 90:10 modified with TC in the presence of $\mathrm{NaOH}$ at $\mathrm{pH} 9$}

The mixing details of binder compositions comprising GA120/GA305 90:10 modified with TC in the presence of $\mathrm{NaOH}$ at $\mathrm{pH} 9$ are listed in Table S7. The binder compositions were mixed using procedures analogous to the representative examples described in the article, using 1.0 $\mathrm{M} \mathrm{NaOH}$ for mixing of the TC mixture (deep red-brown).

\begin{tabular}{|c|c|c|c|c|c|}
\hline Entry & 1 & 2 & 3 & 4 & 5 \\
\hline \multicolumn{6}{|l|}{ Binder composition } \\
\hline GA120 + GA305 & 100 & 100 & 100 & 100 & 100 \\
\hline GA120 (\%-wt. of gelatin) & 90 & 90 & 90 & 90 & 90 \\
\hline GA305 (\%-wt. of gelatin) & 10 & 10 & 10 & 10 & 10 \\
\hline TC (\%-wt. of gelatin) & 0 & 3 & 5 & 10 & 20 \\
\hline \multicolumn{6}{|l|}{ Mixing of binder composition } \\
\hline GA120 (g) & 10.80 & 10.80 & 10.80 & 10.80 & 9.90 \\
\hline GA305 (g) & 1.20 & 1.20 & 1.20 & 1.20 & 1.10 \\
\hline Water $(g)$ & 63.95 & 64.92 & 65.92 & 67.47 & 65.39 \\
\hline $1 \mathrm{M} \mathrm{NaOH}(\mathrm{g})$ & 5.30 & 5.30 & 5.30 & 5.30 & 5.10 \\
\hline $\mathrm{pH}$ & 9.0 & 9.1 & 9.0 & 9.0 & 9.1 \\
\hline TC mixture (g) & 0 & 1.62 & 2.70 & 5.40 & 9.90 \\
\hline $\mathrm{pH}$ & - & 9.0 & 9.0 & 8.9 & 8.9 \\
\hline \multicolumn{6}{|l|}{ Calculated binder composition } \\
\hline Binder concentration ( $\%$-wt. in water) & 15.0 & 15.0 & 15.0 & 15.0 & 15.0 \\
\hline GA120 + GA305 (\%-wt. of gelatin/ & $100.0 /$ & $100.0 /$ & $100.0 /$ & $100.0 /$ & $100.0 /$ \\
\hline \%-wt. of all non-water components) & 98.3 & 95.1 & 93.1 & 88.5 & 80.3 \\
\hline GA120 (\%-wt. of gelatin/ & $90.0 /$ & $90.0 /$ & $90.0 /$ & $90.0 /$ & $90.0 /$ \\
\hline$\%$-wt. of all non-water components) & 88.5 & 85.6 & 83.8 & 79.6 & 72.3 \\
\hline GA305 (\%-wt. of gelatin/ & $10.0 /$ & $10.0 /$ & $10.0 /$ & $10.0 /$ & $10.0 /$ \\
\hline \%-wt. of all non-water components) & 9.8 & 9.5 & 9.3 & 8.8 & 8.0 \\
\hline TC (\%-wt. of gelatin/ & $0 /$ & $3.0 /$ & $5.0 /$ & $10.0 /$ & $20.0 /$ \\
\hline$\%$-wt. of all non-water components) & 0 & 2.9 & 4.7 & 8.8 & 16.1 \\
\hline $\mathrm{NaOH}(\%$-wt. of gelatin/ & 1.7 & $2.1 /$ & $2.4 /$ & $3.0 /$ & $4.5 \%$ \\
\hline$\%$-wt. of all non-water components) & 1.7 & 2.0 & 2.2 & 2.7 & 3.6 \\
\hline
\end{tabular}

TABLE S7. 


\section{Mixing of binder compositions comprising GA120/GB278vs 90:10 modified with TC in the presence of $\mathrm{NaOH}$ at $\mathrm{pH} 9$}

The mixing details of binder compositions comprising GA120/GB278vs 90:10 modified with $\mathrm{TC}$ in the presence of $\mathrm{NaOH}$ at $\mathrm{pH} 9$ are listed in Table S8. The binder compositions were mixed using procedures analogous to the representative examples described in the article, using $1.0 \mathrm{M} \mathrm{NaOH}$ for mixing of the TC mixture (deep red-brown).

\begin{tabular}{|c|c|c|c|c|c|}
\hline Entry & 1 & 2 & 3 & 4 & 5 \\
\hline \multicolumn{6}{|l|}{ Binder composition } \\
\hline GA120 + GB278vs & 100 & 100 & 100 & 100 & 100 \\
\hline GA120 (\%-wt. of gelatin) & 90 & 90 & 90 & 90 & 90 \\
\hline GB278vs (\%-wt. of gelatin) & 10 & 10 & 10 & 10 & 10 \\
\hline TC (\%-wt. of gelatin) & 0 & 3 & 5 & 10 & 20 \\
\hline \multicolumn{6}{|l|}{ Mixing of binder composition } \\
\hline GA120 (g) & 10.80 & 10.80 & 10.80 & 10.80 & 9.90 \\
\hline GB278vs (g) & 1.20 & 1.20 & 1.20 & 1.20 & 1.10 \\
\hline Water (g) & 63.95 & 64.92 & 65.92 & 67.47 & 65.39 \\
\hline $1 \mathrm{M} \mathrm{NaOH}(\mathrm{g})$ & 5.65 & 5.65 & 5.65 & 5.65 & 5.20 \\
\hline $\mathrm{pH}$ & 9.0 & 9.0 & 9.0 & 9.0 & 9.0 \\
\hline TC mixture $(\mathrm{g})$ & 0 & 1.62 & 2.70 & 5.40 & 9.90 \\
\hline $\mathrm{pH}$ & - & 9.0 & 9.0 & 8.9 & 8.9 \\
\hline \multicolumn{6}{|l|}{ Calculated binder composition } \\
\hline Binder concentration ( $\%$-wt. in water) & 15.0 & 15.0 & 15.0 & 15.0 & 15.0 \\
\hline GA120 + GB278vs (\%-wt. of gelatin/ & $100.0 /$ & $100.0 /$ & $100.0 /$ & $100.0 /$ & $100.0 /$ \\
\hline \%-wt. of all non-water components) & 98.2 & 95.0 & 93.0 & 88.4 & 80.3 \\
\hline GA120 (\%-wt. of gelatin/ & $90.0 /$ & $90.0 /$ & $90.0 /$ & $90.0 /$ & $90.0 /$ \\
\hline$\%$-wt. of all non-water components) & 88.4 & 85.5 & 83.7 & 79.5 & 72.3 \\
\hline GB278vs (\%-wt. of gelatin/ & $10.0 /$ & $10.0 /$ & $10.0 /$ & $10.0 /$ & $10.0 /$ \\
\hline$\%$-wt. of all non-water components) & 9.8 & 9.5 & 9.3 & 8.8 & 8.0 \\
\hline TC (\%-wt. of gelatin/ & $0 /$ & $3.0 /$ & $5.0 /$ & $10.0 /$ & $20.0 /$ \\
\hline$\%$-wt. of all non-water components) & 0 & 2.9 & 4.7 & 8.8 & 16.1 \\
\hline $\mathrm{NaOH}(\%$-wt. of gelatin/ & $1.8 /$ & $2.2 \%$ & $2.5 \%$ & $3.2 \%$ & $4.5 /$ \\
\hline$\%$-wt. of all non-water components) & 1.8 & 2.1 & 2.3 & 2.8 & 3.6 \\
\hline
\end{tabular}

TABLE S8. 
Mixing of binder compositions comprising GA120 modified with TA in the presence of $\mathrm{NaOH}$ at pH 9

The mixing details of binder compositions comprising GA120 modified with TA in the presence of $\mathrm{NaOH}$ at $\mathrm{pH} 9$ are listed in Table S9. The binder compositions were mixed using procedures analogous to the representative examples described in the article, using $1.5 \mathrm{M}$ $\mathrm{NaOH}$ for mixing of the TA mixture (green-brownish, $\mathrm{pH} 9.2$ ).

\begin{tabular}{|c|c|c|c|c|c|c|c|}
\hline Entry & 1 & 2 & 3 & 4 & 5 & 6 & 7 \\
\hline \multicolumn{8}{|l|}{ Binder composition } \\
\hline GA120 & 100 & 100 & 100 & 100 & 100 & 100 & 100 \\
\hline TA (\%-wt. of gelatin) & 0 & 3 & 5 & 10 & 20 & 30 & 50 \\
\hline \multicolumn{8}{|l|}{ Mixing of binder composition } \\
\hline GA120 (g) & 14.00 & 12.00 & 12.00 & 12.00 & 12.00 & 11.00 & 9.50 \\
\hline Water $(\mathrm{g})$ & 75.17 & 64.43 & 65.42 & 66.95 & 70.76 & 68.14 & 64.14 \\
\hline $1 \mathrm{M} \mathrm{NaOH}(\mathrm{g})$ & 5.16 & 6.22 & 6.43 & 6.75 & 7.49 & 7.70 & 8.26 \\
\hline $\mathrm{pH}$ & 9.1 & 9.4 & 9.5 & 9.8 & 10.0 & 10.4 & 11.1 \\
\hline TA mixture $(\mathrm{g})$ & 0 & 1.62 & 2.70 & 5.40 & 10.80 & 14.85 & 21.38 \\
\hline $\mathrm{pH}$ & - & 9.3 & 9.3 & 9.4 & 9.3 & 9.3 & 9.3 \\
\hline \multicolumn{8}{|l|}{ Calculated binder composition } \\
\hline Binder concentration (\%-wt. in water) & 15.1 & 15.0 & 15.0 & 15.0 & 15.0 & 15.0 & 15.0 \\
\hline GA120 (\%-wt. of gelatin/ & $100.0 /$ & $100.0 /$ & $100.0 /$ & $100.0 /$ & $100.0 /$ & $100.0 /$ & $100.0 /$ \\
\hline$\%$-wt. of all non-water components) & 98.6 & 94.7 & 95.2 & 87.6 & 79.1 & 72.1 & 61.3 \\
\hline TA (\%-wt. of gelatin/ & $0 /$ & $3.0 /$ & $5.0 \%$ & $10.0 /$ & $20.0 /$ & $30.0 /$ & $50.0 /$ \\
\hline$\%$-wt. of all non-water components) & 0 & 2.8 & 4.6 & 8.8 & 15.8 & 21.6 & 30.6 \\
\hline $\mathrm{NaOH}(\%$-wt. of gelatin/ & $1.4 \%$ & $2.6 /$ & $3.1 /$ & 4.11 & $6.4 i$ & $8.6 \%$ & $13.3 /$ \\
\hline$\%$-wt. of all non-water components) & 1.4 & 2.5 & 2.8 & 3.6 & 5.0 & 6.2 & 8.1 \\
\hline
\end{tabular}

TABLE S9. 
Mixing of binder compositions comprising GA120 modified with TG in the presence of $\mathrm{NaOH}$ at pH 9

The mixing details of binder compositions comprising GA120 modified with TG in the presence of $\mathrm{NaOH}$ at $\mathrm{pH} 9$ are listed in Table S10. The binder compositions were mixed using procedures analogous to the representative examples described in the article, using $0.7 \mathrm{M}$ $\mathrm{NaOH}$ for mixing of the TG mixture (brownish, slightly hazy, $\mathrm{pH} 9.0$ ).

\begin{tabular}{|c|c|c|c|c|c|c|c|}
\hline Entry & 1 & 2 & 3 & 4 & 5 & 6 & 7 \\
\hline \multicolumn{8}{|l|}{ Binder composition } \\
\hline GA120 & 100 & 100 & 100 & 100 & 100 & 100 & 100 \\
\hline TG (\%-wt. of gelatin) & 0 & 3 & 5 & 10 & 20 & 30 & 50 \\
\hline \multicolumn{8}{|l|}{ Mixing of binder composition } \\
\hline GA120 (g) & 14.00 & 12.00 & 12.00 & 12.00 & 12.00 & 11.00 & 9.50 \\
\hline Water $(\mathrm{g})$ & 75.17 & 64.92 & 65.92 & 67.47 & 70.76 & 68.14 & 64.14 \\
\hline $1 \mathrm{M} \mathrm{NaOH}(\mathrm{g})$ & 5.16 & 5.20 & 5.20 & 5.20 & 5.20 & 4.85 & 4.10 \\
\hline $\mathrm{pH}$ & 9.1 & 9.3 & 9.2 & 9.2 & 9.3 & 9.2 & 9.1 \\
\hline TG mixture $(\mathrm{g})$ & 0 & 1.62 & 2.70 & 5.40 & 10.80 & 14.85 & 21.38 \\
\hline $\mathrm{pH}$ & - & 9.1 & 9.0 & 9.0 & 9.0 & 9.0 & 9.0 \\
\hline \multicolumn{8}{|l|}{ Calculated binder composition } \\
\hline Binder concentration (\%-wt. in water) & 15.1 & 15.0 & 15.0 & 15.0 & 15.0 & 15.0 & 15.0 \\
\hline GA120 (\%-wt. of gelatin/ & $100.0 /$ & $100.0 /$ & $100.0 /$ & $100.0 /$ & $100.0 /$ & $100.0 /$ & $100.0 /$ \\
\hline$\%$-wt. of all non-water components) & 98.6 & 95.3 & 93.3 & 88.8 & 80.9 & 74.3 & 63.9 \\
\hline TG (\%-wt. of gelatin/ & $0 /$ & $3.0 /$ & $5.0 \%$ & $10.0 /$ & $20.0 \%$ & $30.0 \%$ & $50.0 /$ \\
\hline$\%$-wt. of all non-water components) & 0 & 2.9 & 4.7 & 8.9 & 16.2 & 22.3 & 32.0 \\
\hline $\mathrm{NaOH}(\%$-wt. of gelatin/ & $1.4 \%$ & $2.0 /$ & $2.1 /$ & $2.6 \%$ & $3.6 \%$ & 4.67 & $6.4 /$ \\
\hline$\%$-wt. of all non-water components) & 1.4 & 1.9 & 2.0 & 2.3 & 2.9 & 3.4 & 4.1 \\
\hline
\end{tabular}

TABLE S10. 
Mixing of binder compositions comprising GA120 modified with TO in the presence of $\mathrm{NaOH}$ at pH 9

The mixing details of binder compositions comprising GA120 modified with TO in the presence of $\mathrm{NaOH}$ at $\mathrm{pH} 9$ are listed in Table S11. The binder compositions were mixed using procedures analogous to the representative examples described in the article.

\begin{tabular}{|c|c|c|c|c|c|c|c|}
\hline Entry & 1 & 2 & 3 & 4 & 5 & 6 & 7 \\
\hline \multicolumn{8}{|l|}{ Binder composition } \\
\hline GA120 & 100 & 100 & 100 & 100 & 100 & 100 & 100 \\
\hline TO (\%-wt. of gelatin) & 0 & 3 & 5 & 10 & 20 & 30 & 50 \\
\hline \multicolumn{8}{|l|}{ Mixing of binder composition } \\
\hline GA120 (g) & 14.00 & 12.00 & 12.00 & 12.00 & 12.00 & 11.00 & 9.50 \\
\hline Water $(\mathrm{g})$ & 75.17 & 64.92 & 65.42 & 67.47 & 70.76 & 68.14 & 64.72 \\
\hline $1 \mathrm{M} \mathrm{NaOH}(\mathrm{g})$ & 5.16 & 5.90 & 5.90 & 5.90 & 5.90 & 5.60 & 4.65 \\
\hline $\mathrm{pH}$ & 9.1 & 9.0 & 9.1 & 9.1 & 9.1 & 9.1 & 9.1 \\
\hline TO mixture $(\mathrm{g})$ & 0 & 1.62 & 2.70 & 5.40 & 10.80 & 14.85 & 21.38 \\
\hline $\mathrm{pH}$ & - & 9.0 & 9.0 & 9.0 & 9.0 & 9.1 & 9.0 \\
\hline \multicolumn{8}{|l|}{ Calculated binder composition } \\
\hline Binder concentration (\%-wt. in water) & 15.1 & 15.0 & 15.0 & 15.0 & 15.0 & 15.0 & 15.0 \\
\hline GA120 (\%-wt. of gelatin/ & $100.0 \%$ & $100.0 /$ & $100.0 /$ & $100.0 /$ & $100.0 \%$ & $100.0 /$ & $100.0 \%$ \\
\hline$\%$-wt. of all non-water components) & 98.6 & 95.0 & 93.0 & 88.4 & 80.4 & 73.7 & 63.3 \\
\hline TO (\%-wt. of gelatin/ & $0 /$ & $3.0 /$ & $5.0 \%$ & $10.0 \%$ & $20.0 /$ & $30.0 /$ & $50.0 \%$ \\
\hline$\%$-wt. of all non-water components) & 0 & 2.9 & 4.7 & 8.8 & 16.1 & 22.1 & 31.7 \\
\hline $\mathrm{NaOH}(\%$-wt. of gelatin/ & $1.4 \%$ & $2.3 \%$ & $2.5 /$ & 3.11 & $4.3 /$ & $5.6 /$ & $8.0 /$ \\
\hline$\%$-wt. of all non-water components) & 1.4 & 2.1 & 2.3 & 2.7 & 3.5 & 4.1 & 5.0 \\
\hline
\end{tabular}

TABLE S11. 
Mixing of binder compositions comprising GA120 modified with TQ in the presence of $\mathrm{NaOH}$ at pH 9

The mixing details of binder compositions comprising GA120 modified with TQ in the presence of $\mathrm{NaOH}$ at $\mathrm{pH} 9$ are listed in Table S12. The binder compositions were mixed using procedures analogous to the representative examples described in the article, using $0.5 \mathrm{M}$ $\mathrm{NaOH}$ for mixing of the TQ mixture (brownish, $\mathrm{pH} 9.2$ ).

\begin{tabular}{|c|c|c|c|c|c|c|c|}
\hline Entry & 1 & 2 & 3 & 4 & 5 & 6 & 7 \\
\hline \multicolumn{8}{|l|}{ Binder composition } \\
\hline GA120 & 100 & 100 & 100 & 100 & 100 & 100 & 100 \\
\hline TQ (\%-wt. of gelatin) & 0 & 3 & 5 & 10 & 20 & 30 & 50 \\
\hline \multicolumn{8}{|l|}{ Mixing of binder composition } \\
\hline $\mathrm{GA} 120(\mathrm{~g})$ & 14.00 & 12.00 & 12.00 & 12.00 & 12.00 & 11.00 & 9.50 \\
\hline Water $(\mathrm{g})$ & 75.17 & 64.43 & 64.92 & 66.43 & 69.63 & 67.01 & 63.02 \\
\hline $1 \mathrm{M} \mathrm{NaOH}(\mathrm{g})$ & 5.16 & 5.90 & 6.00 & 6.00 & 6.00 & 5.50 & 4.75 \\
\hline $\mathrm{pH}$ & 9.1 & 9.1 & 9.1 & 9.1 & 9.1 & 9.1 & 9.1 \\
\hline TQ mixture (g) & 0 & 1.62 & 2.70 & 5.40 & 10.80 & 14.85 & 21.38 \\
\hline $\mathrm{pH}$ & - & 9.1 & 9.0 & 9.0 & 9.1 & 9.0 & 9.0 \\
\hline \multicolumn{8}{|l|}{ Calculated binder composition } \\
\hline Binder concentration ( $\%$-wt. in water) & 15.1 & 15.0 & 15.0 & 15.0 & 15.0 & 15.0 & 15.0 \\
\hline GA120 (\%-wt. of gelatin/ & $100.0 /$ & $100.0 \%$ & $100.0 /$ & $100.0 \%$ & $100.0 \%$ & $100.0 \%$ & $100.0 /$ \\
\hline$\%$-wt. of all non-water components) & 98.6 & 95.1 & 93.2 & 88.8 & 81.1 & 76.4 & 64.4 \\
\hline TQ (\%-wt. of gelatin/ & $0 /$ & $3.0 /$ & $5.0 \%$ & $10.0 \%$ & $20.0 \%$ & $30.0 /$ & $50.0 \%$ \\
\hline$\%$-wt. of all non-water components) & 0 & 2.9 & 4.7 & 8.9 & 16.2 & 22.4 & 32.2 \\
\hline $\mathrm{NaOH}(\%-w t$ of gelatin/ & $1.4 \%$ & $2.1 \%$ & $2.3 \%$ & $2.6 \%$ & $3.3 /$ & $4.0 \%$ & $5.47^{-}$ \\
\hline$\%$-wt. of all non-water components) & 1.4 & 2.0 & 2.1 & 2.3 & 2.7 & 3.0 & 3.4 \\
\hline
\end{tabular}

TABLE S12. 


\section{Mixing of binder compositions comprising GA120 modified with TC in the presence of KOH at pH 9}

The mixing details of binder compositions comprising GA120 modified with TC in the presence of $\mathrm{KOH}$ at $\mathrm{pH} 9$ are listed in Table S13. The binder compositions were mixed using procedures analogous to the representative examples described in the article, using 1.0 $\mathrm{M} \mathrm{KOH}$ both for $\mathrm{pH}$ adjustment and for mixing of the TC mixture (deep red-brown, traces of precipitates).

\begin{tabular}{lccccc}
\hline Entry & $\mathbf{1}$ & $\mathbf{2}$ & $\mathbf{3}$ & $\mathbf{4}$ & $\mathbf{5}$ \\
\hline Binder composition & & & & & \\
GA120 & 100 & 100 & 100 & 100 & 100 \\
TC (\%-wt. of gelatin) & 0 & 3 & 5 & 10 & 20 \\
\hline Mixing of binder composition & & & & & \\
GA120 (g) & 12.00 & 12.00 & 12.00 & 12.00 & 11.00 \\
Water (g) & 64.92 & 66.43 & 66.95 & 69.08 & 67.01 \\
1M KOH (g) & 4.70 & 4.70 & 4.70 & 4.70 & 4.30 \\
pH & 9.2 & 9.2 & 9.1 & 9.1 & 9.1 \\
TC mixture (g) & 0 & 1.62 & 2.70 & 5.40 & 9.90 \\
pH & - & 9.1 & 9.1 & 9.0 & 8.9 \\
\hline Calculated binder composition & & & & & \\
Binder concentration (\%-wt. in water) & 15.0 & 15.0 & 15.0 & 15.0 & 15.0 \\
\hline GA120 (\%-wt. of gelatin/ & $100.0 /$ & $100.0 /$ & $100.0 /$ & $100.0 /$ & $100.0 /$ \\
\%-wt. of all non-water components) & 98.0 & 94.7 & 92.6 & 87.8 & 79.5 \\
\hline TC (\%-wt. of gelatin/ & $0 /$ & $3.0 /$ & $5.0 /$ & $10.0 /$ & $20.0 /$ \\
\%-wt. of all non-water components) & 0 & 2.8 & 4.6 & 8.8 & 15.9 \\
\hline KOH (\%-wt. of gelatin/ & $2.1 /$ & $2.6 /$ & $3.0 /$ & $3.9 /$ & $5.8 /$ \\
\%-wt. of all non-water components) & 2.0 & 2.5 & 2.8 & 3.5 & 4.6 \\
\hline
\end{tabular}

TABLE S13. 
Mixing of binder compositions comprising GA120 modified with TC in the presence of

\section{LiOH at pH 9}

The mixing details of binder compositions comprising GA120 modified with TC in the presence of $\mathrm{LiOH}$ at $\mathrm{pH} 9$ are listed in the Table S14. The binder compositions were mixed using procedures analogous to the representative examples described in the article, using 1.0 $\mathrm{M} \mathrm{LiOH}$ both for $\mathrm{pH}$ adjustment and for mixing of the TC mixture (deep red-brown, $\mathrm{pH}$ 9.2).

\begin{tabular}{|c|c|c|c|c|c|}
\hline Entry & 1 & 2 & 3 & 4 & 5 \\
\hline \multicolumn{6}{|l|}{ Binder composition } \\
\hline GA120 & 100 & 100 & 100 & 100 & 100 \\
\hline TC (\%-wt. of gelatin) & 0 & 3 & 5 & 10 & 20 \\
\hline \multicolumn{6}{|l|}{ Mixing of binder composition } \\
\hline GA120 (g) & 12.00 & 12.00 & 12.00 & 12.00 & 11.00 \\
\hline Water (g) & 64.43 & 65.42 & 65.92 & 67.47 & 64.86 \\
\hline $1 \mathrm{M} \mathrm{LiOH}(\mathrm{g})$ & 4.30 & 4.30 & 4.30 & 4.30 & 3.95 \\
\hline $\mathrm{pH}$ & 9.2 & 9.1 & 9.1 & 9.1 & 9.2 \\
\hline TC mixture (g) & 0 & 1.62 & 2.70 & 5.40 & 9.90 \\
\hline $\mathrm{pH}$ & - & 9.1 & 9.2 & 9.1 & 9.2 \\
\hline \multicolumn{6}{|l|}{ Calculated binder composition } \\
\hline Binder concentration ( $\%$-wt. in water) & 15.0 & 15.0 & 15.0 & 15.0 & 15.0 \\
\hline GA120 (\%-wt. of gelatin/ & $100.0 /$ & $100.0 /$ & $100.0 /$ & $100.0 \%$ & $100.0 /$ \\
\hline$\%$-wt. of all non-water components) & 99.2 & 96.1 & 94.1 & 89.6 & 81.6 \\
\hline TC (\%-wt. of gelatin/ & $0 /$ & $3.0 \%$ & $5.0 \%$ & $10.0 \%$ & $20.0 /$ \\
\hline$\%$-wt. of all non-water components) & 0 & 2.9 & 4.7 & 9.0 & 16.3 \\
\hline $\mathrm{LiOH}(\%-w t . ~ o f ~ g e l a t i n /$ & $0.8 \%$ & $1.1 \%$ & $1.2 \%$ & $1.7 /$ & $2.5 /$ \\
\hline$\%$-wt. of all non-water components) & 0.8 & 1.0 & 1.2 & 1.5 & 2.0 \\
\hline
\end{tabular}

TABLE S14. 


\section{Mixing of binder compositions comprising GA120 modified with TC in the presence of $\mathrm{Ca}(\mathrm{OH})_{2}$ at $\mathrm{pH} 9$}

Mixing details about binder compositions comprising GA120 modified with TC in the presence of $\mathrm{Ca}(\mathrm{OH})_{2}$ at $\mathrm{pH} 9$ have been partly disclosed previously. ${ }^{\mathrm{S} 2}$ The complete mixing details are listed in the Table S15. The binder compositions (all containing precipitates) were mixed using procedures analogous to the representative examples described in the article, using a stirred suspension of $\mathrm{Ca}(\mathrm{OH})_{2}$ in water corresponding to $0.5 \mathrm{M} \mathrm{Ca}(\mathrm{OH})_{2}$ both for $\mathrm{pH}$ adjustment and for mixing of the TC mixture (deep brown, paste/thick suspension, $\mathrm{pH} 8.0$ ).

\begin{tabular}{|c|c|c|c|c|c|}
\hline Entry & 1 & 2 & 3 & 4 & 5 \\
\hline \multicolumn{6}{|l|}{ Binder composition } \\
\hline GA120 & 100 & 100 & 100 & 100 & 100 \\
\hline TC (\%-wt. of gelatin) & 0 & 3 & 5 & 10 & 20 \\
\hline \multicolumn{6}{|l|}{ Mixing of binder composition } \\
\hline GA120 (g) & 12.00 & 12.00 & 12.00 & 12.00 & 11.00 \\
\hline Water (g) & 64.43 & 65.42 & 65.92 & 66.95 & 62.83 \\
\hline $0.5 \mathrm{M} \mathrm{Ca}(\mathrm{OH})_{2}(\mathrm{~g})$ & 4.40 & 4.86 & 5.31 & 6.00 & 8.17 \\
\hline $\mathrm{pH}$ & 9.2 & 9.4 & 9.6 & 10.1 & 10.7 \\
\hline TC mixture (g) & 0 & 1.62 & 2.70 & 5.40 & 9.90 \\
\hline $\mathrm{pH}$ & - & 9.2 & 9.2 & 9.1 & 9.1 \\
\hline \multicolumn{6}{|l|}{ Calculated binder composition } \\
\hline Binder concentration (\%-wt. in water) & 15.0 & 15.0 & 15.0 & 15.0 & 15.0 \\
\hline GA120 (\%-wt. of gelatin/ & $100.0 /$ & $100.0 \%$ & $100.0 \%$ & $100.0 \%$ & $100.0 /$ \\
\hline$\%$-wt. of all non-water components) & 98.7 & 95.4 & 93.3 & 88.5 & 79.9 \\
\hline TC (\%-wt. of gelatin/ & $0 /$ & $3.0 \%$ & $5.0 /$ & $10.0 /$ & $20.0 /$ \\
\hline$\%$-wt. of all non-water components) & 0 & 2.9 & 4.7 & 8.8 & 16.0 \\
\hline $\mathrm{Ca}(\mathrm{OH})_{2}(\%$-wt. of gelatin/ & $1.3 \%^{\prime}$ & $1.8 \%$ & $2.2 \%$ & $3.0 /$ & $5.2 \%$ \\
\hline$\%$-wt. of all non-water components) & 1.3 & 1.7 & 2.1 & 2.7 & 4.1 \\
\hline
\end{tabular}

TABLE S15. 


\section{Mixing of binder compositions comprising GA120 modified with TC in the presence of $\mathrm{NaOH}$ at $\mathrm{pH} 7$}

The mixing details of binder compositions comprising GA120 modified with TC in the presence of $\mathrm{NaOH}$ at $\mathrm{pH} 7$ are listed in Table S16. The binder compositions were mixed using procedures analogous to the representative examples described in the article, using $0.5 \mathrm{M}$ $\mathrm{NaOH}$ for mixing of the TC mixture (deep red-brown, $\mathrm{pH}$ 7.2) and adjusting the final $\mathrm{pH}$ to 7 with $1.0 \mathrm{M} \mathrm{NaOH}$.

\begin{tabular}{lccccc}
\hline Entry & $\mathbf{1}$ & $\mathbf{2}$ & $\mathbf{3}$ & $\mathbf{4}$ & $\mathbf{5}$ \\
\hline Binder composition & & & & & \\
GA120 & 100 & 100 & 100 & 100 & 100 \\
TC (\%-wt. of gelatin) & 0 & 3 & 5 & 10 & 20 \\
\hline Mixing of binder composition & & & & & \\
GA120 (g) & 12.00 & 12.00 & 12.00 & 12.00 & 11.00 \\
Water (g) & 65.42 & 66.43 & 66.95 & 69.08 & 66.46 \\
1M NaOH (g) & 3.10 & 3.10 & 3.10 & 3.35 & 3.30 \\
pH & 7.1 & 7.0 & 7.0 & 7.1 & 7.2 \\
TC mixture (g) & 0 & 1.62 & 2.70 & 5.40 & 9.90 \\
pH & - & 6.9 & 6.9 & 6.9 & 6.9 \\
\hline Calculated binder composition & & & & & \\
Binder concentration (\%-wt. in water) & 15.1 & 15.0 & 15.1 & 14.9 & 14.9 \\
\hline GA120 (\%-wt. of gelatin/ & $100.0 /$ & $100.0 /$ & $100.0 /$ & $100.0 /$ & $100.0 /$ \\
\%-wt. of all non-water components) & 99.0 & 96.0 & 94.0 & 89.5 & 81.6 \\
\hline TC (\%-wt. of gelatin/ & $0 /$ & $3.0 /$ & $5.0 /$ & $10.0 /$ & $20.0 /$ \\
\%-wt. of all non-water components) & 0 & 2.9 & 4.7 & 8.9 & 16.3 \\
\hline NaOH (\%-wt. of gelatin/ & $1.0 /$ & $1.2 /$ & $1.3 /$ & $1.8 /$ & $2.5 /$ \\
\%-wt. of all non-water components) & 1.0 & 1.2 & 1.3 & 1.6 & 2.1 \\
\hline
\end{tabular}

TABLE S16. 


\section{Mixing of binder compositions comprising GA120 modified with TC in the presence of $\mathrm{NaOH}$ at pH 8}

The mixing details of binder compositions comprising GA120 modified with TC in the presence of $\mathrm{NaOH}$ at $\mathrm{pH} 8$ are listed in Table S17. The binder compositions were mixed using procedures analogous to the representative examples described in the article, using $0.7 \mathrm{M}$ $\mathrm{NaOH}$ for mixing of the TC mixture (deep red-brown, $\mathrm{pH} 8.0$ ) and adjusting the final $\mathrm{pH}$ to 8 with $1.0 \mathrm{M} \mathrm{NaOH}$.

\begin{tabular}{lccccc}
\hline Entry & $\mathbf{1}$ & $\mathbf{2}$ & $\mathbf{3}$ & $\mathbf{4}$ & $\mathbf{5}$ \\
\hline Binder composition & & & & & \\
GA120 & 100 & 100 & 100 & 100 & 100 \\
TC (\%-wt. of gelatin) & 0 & 3 & 5 & 10 & 20 \\
\hline Mixing of binder composition & & & & & \\
GA120 (g) & 12.00 & 12.00 & 12.00 & 12.00 & 11.00 \\
Water (g) & 64.92 & 65.92 & 66.43 & 68.00 & 65.39 \\
1M NaOH (g) & 4.35 & 4.40 & 4.40 & 4.70 & 5.15 \\
pH & 8.2 & 8.1 & 8.2 & 8.3 & 8.4 \\
TC mixture (g) & 0 & 1.62 & 2.70 & 5.40 & 9.90 \\
pH & - & 7.9 & 7.9 & 7.9 & 8.0 \\
\hline Calculated binder composition & & & & & \\
Binder concentration (\%-wt. in water) & 15.0 & 15.0 & 15.0 & 15.0 & 14.9 \\
\hline GA120 (\%-wt. of gelatin/ & $100.0 /$ & $100.0 /$ & $100.0 /$ & $100.0 /$ & $100.0 /$ \\
\%-wt. of all non-water components) & 98.6 & 95.5 & 93.6 & 88.9 & 80.8 \\
\hline TC (\%-wt. of gelatin/ & $0 /$ & $3.0 /$ & $5.0 /$ & $10.0 /$ & $20.0 /$ \\
\%-wt. of all non-water components) & 0 & 2.9 & 4.7 & 8.9 & 16.2 \\
\hline NaOH (\%-wt. of gelatin/ & $1.4 /$ & $1.7 /$ & $1.9 /$ & $2.5 /$ & $3.7 /$ \\
\%-wt. of all non-water components) & 1.4 & 1.6 & 1.8 & 2.2 & 3.0 \\
\hline
\end{tabular}

TABLE S17. 


\section{Mixing of binder compositions comprising GA120 modified with TC in the presence of $\mathrm{NaOH}$ at pH 11}

The mixing details of binder compositions comprising GA120 modified with TC in the presence of $\mathrm{NaOH}$ at $\mathrm{pH} 11$ are listed in Table S18. The binder compositions were mixed using procedures analogous to the representative examples described in the article, using $1.5 \mathrm{M}$ $\mathrm{NaOH}$ for mixing of the TC mixture (deep red-brown, $\mathrm{pH} 10.9$ ) and adjusting the final $\mathrm{pH}$ to 11 with $1.0 \mathrm{M} \mathrm{NaOH}$.

\begin{tabular}{lccccc}
\hline Entry & $\mathbf{1}$ & $\mathbf{2}$ & $\mathbf{3}$ & $\mathbf{4}$ & $\mathbf{5}$ \\
\hline Binder composition & & & & & \\
GA120 & 100 & 100 & 100 & 100 & 100 \\
TC (\%-wt. of gelatin) & 0 & 3 & 5 & 10 & 20 \\
\hline Mixing of binder composition & & & & & \\
GA120 (g) & 12.00 & 12.00 & 12.00 & 12.00 & 11.00 \\
Water (g) & 60.29 & 61.62 & 62.53 & 64.43 & 63.32 \\
1M NaOH (g) & 10.10 & 10.00 & 10.50 & 10.90 & 11.20 \\
pH & 11.1 & 11.0 & 11.0 & 11.1 & 11.3 \\
TC mixture (g) & 0 & 1.62 & 2.70 & 5.40 & 9.90 \\
pH & - & 10.9 & 10.9 & 10.9 & 10.8 \\
\hline Calculated binder composition & & & & & \\
Binder concentration (\%-wt. in water) & 15.0 & 15.0 & 15.0 & 15.0 & 14.8 \\
\hline GA120 (\%-wt. of gelatin/ & $100.0 /$ & $100.0 /$ & $100.0 /$ & $100.0 /$ & $100.0 /$ \\
\%-wt. of all non-water components) & 96.9 & 93.6 & 91.4 & 86.5 & 78.1 \\
\hline TC (\%-wt. of gelatin/ & $0 /$ & $3.0 /$ & $5.0 /$ & $10.0 /$ & $20.0 /$ \\
\%-wt. of all non-water components) & 0 & 2.8 & 4.6 & 8.7 & 15.6 \\
\hline NaOH (\%-wt. of gelatin/ & 3.1 & 3.6 & 4.0 & 4.8 & 6.3 \\
\hline -wt. of all non-water components) & 3.1 & $3.8 /$ & $4.4 /$ & $5.6 /$ & $8.0 /$ \\
\hline
\end{tabular}

TABLE S18. 


\section{FURTHER DETAILED RESULTS FOR COMPOSITE BARS}

\section{Results for binder compositions comprising GA78 modified with TC in the presence of $\mathrm{NaOH}$ at $\mathrm{pH} 9$}

Details about mechanical strengths and binder contents for binder compositions comprising GA78 modified with TC in the presence of $\mathrm{NaOH}$ at $\mathrm{pH} 9$ have been published previously. ${ }^{(\mathrm{S} 1)}$ The water uptake results for binder compositions comprising GA78 modified with TC in the presence of $\mathrm{NaOH}$ at $\mathrm{pH} 9$ are shown in Table S19 and Figure S4.

\begin{tabular}{lccccccc}
\hline Entry & $\mathbf{1}$ & $\mathbf{2}$ & $\mathbf{3}$ & $\mathbf{4}$ & $\mathbf{5}$ & $\mathbf{6}$ & $\mathbf{7}$ \\
\hline Binder composition & & & & & & & \\
GA78 & 100 & 100 & 100 & 100 & 100 & 100 & 100 \\
TC (\%-wt. of gelatin) & 0 & 3 & 5 & 10 & 20 & 30 & 50 \\
\hline Composite bar results & & & & & & & \\
Avg. water uptake, $3 \mathrm{~h}(\%, \mathrm{n}=3)$ & 7.1 & 12.3 & 13.7 & 17.9 & 21.2 & 22.5 & 23.8 \\
Standard error $(\%)$ & 0.3 & 0.8 & 0.7 & 1.7 & 2.0 & 1.6 & 1.6 \\
\hline $\begin{array}{l}\text { Avg. water uptake, } 24 \mathrm{~h}(\%, \mathrm{n}=3) \\
\text { Standard error }(\%)\end{array}$ & 12.4 & 24.7 & 27.8 & 31.7 & 37.4 & 38.4 & 45.2 \\
\hline
\end{tabular}

TABLE S19.

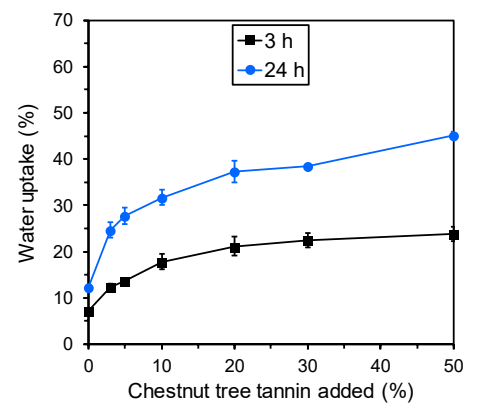

FIGURE S4. 


\section{Results for binder compositions comprising GA120 modified with TC in the presence of $\mathrm{NaOH}$ at pH 9}

Details about mechanical strengths and binder contents for binder compositions comprising GA120 modified with TC in the presence of $\mathrm{NaOH}$ at $\mathrm{pH} 9$ have been published previously. ${ }^{\text {(S1) }}$ The water uptake results for binder compositions comprising GA120 modified with TC in the presence of $\mathrm{NaOH}$ at $\mathrm{pH} 9$ are shown in Table S20 and Figure S5.

\begin{tabular}{lccccccc}
\hline Entry & $\mathbf{1}$ & $\mathbf{2}$ & $\mathbf{3}$ & $\mathbf{4}$ & $\mathbf{5}$ & $\mathbf{6}$ & $\mathbf{7}$ \\
\hline Binder composition & & & & & & & \\
GA120 & 100 & 100 & 100 & 100 & 100 & 100 & 100 \\
TC (\%-wt. of gelatin) & 0 & 3 & 5 & 10 & 20 & 30 & 50 \\
\hline Composite bar results & & & & & & & \\
Avg. water uptake, $3 \mathrm{~h}(\%, \mathrm{n}=3)$ & 5.8 & 11.9 & 15.3 & 18.0 & 18.4 & 19.2 & 20.3 \\
Standard error $(\%)$ & 0.1 & 0.5 & 0.8 & 0.9 & 1.8 & 0.2 & 1.0 \\
\hline $\begin{array}{l}\text { Avg. water uptake, } 24 \mathrm{~h}(\%, \mathrm{n}=3) \\
\text { Standard error }(\%)\end{array}$ & 11.2 & 26.0 & 26.8 & 32.7 & 33.0 & 35.8 & 38.1 \\
\hline
\end{tabular}

TABLE S20.

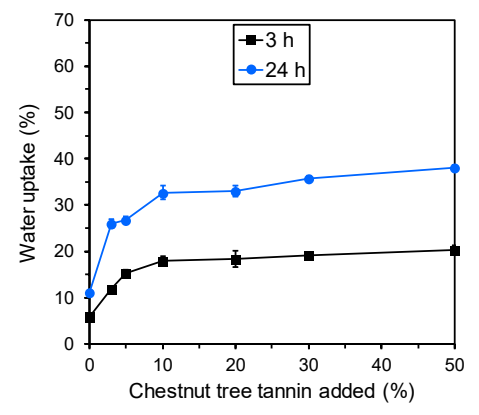

FIGURE S5. 


\section{Results for binder compositions comprising GA180 modified with TC in the presence of $\mathrm{NaOH}$ at pH 9}

Details about mechanical strengths and binder contents for binder compositions comprising GA180 modified with TC in the presence of $\mathrm{NaOH}$ at $\mathrm{pH} 9$ have been published previously. ${ }^{\text {(S1) }}$ The water uptake results for binder compositions comprising GA180 modified with TC in the presence of $\mathrm{NaOH}$ at $\mathrm{pH} 9$ are shown in Table S21 and Figure S6.

\begin{tabular}{lccccccc}
\hline Entry & $\mathbf{1}$ & $\mathbf{2}$ & $\mathbf{3}$ & $\mathbf{4}$ & $\mathbf{5}$ & $\mathbf{6}$ & $\mathbf{7}$ \\
\hline Binder composition & & & & & & & \\
GA180 & 100 & 100 & 100 & 100 & 100 & 100 & 100 \\
TC (\%-wt. of gelatin) & 0 & 3 & 5 & 10 & 20 & 30 & 50 \\
\hline Composite bar results & & & & & & & \\
Avg. water uptake, $3 \mathrm{~h}(\%, \mathrm{n}=3)$ & 5.6 & 9.4 & 10.1 & 12.5 & 13.7 & 13.0 & 16.0 \\
Standard error (\%) & 0.2 & 0.3 & 0.9 & 0.6 & 0.4 & 0.4 & 1.0 \\
\hdashline Avg. water uptake, $24 \mathrm{~h}(\%, \mathrm{n}=3)$ & 10.4 & 20.4 & 20.7 & 25.6 & 30.7 & 29.5 & 33.5 \\
Standard error $(\%)$ & 0.2 & 0.3 & 0.6 & 1.0 & 1.0 & 2.2 & 1.6 \\
\hline
\end{tabular}

TABLE S21.

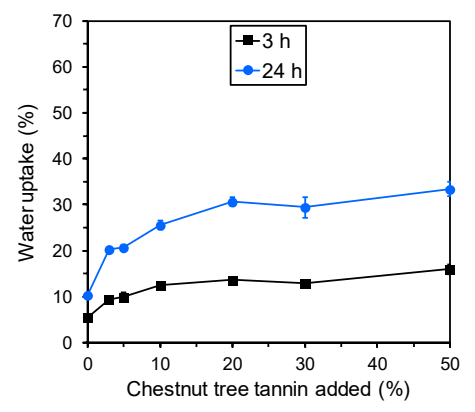

FIGURE S6. 


\section{Results for binder compositions comprising GA305 modified with TC in the presence of $\mathrm{NaOH}$ at pH 9}

Details about mechanical strengths and binder contents for binder compositions comprising GA305 modified with TC in the presence of $\mathrm{NaOH}$ at $\mathrm{pH} 9$ have been published previously. ${ }^{\text {(S1) }}$ The water uptake results for binder compositions comprising GA305 modified with TC in the presence of $\mathrm{NaOH}$ at $\mathrm{pH} 9$ are shown in Table S22 and Figure S7.

\begin{tabular}{lccccccc}
\hline Entry & $\mathbf{1}$ & $\mathbf{2}$ & $\mathbf{3}$ & $\mathbf{4}$ & $\mathbf{5}$ & $\mathbf{6}$ & $\mathbf{7}$ \\
\hline Binder composition & & & & & & & \\
GA305 & 100 & 100 & 100 & 100 & 100 & 100 & 100 \\
TC (\%-wt. of gelatin) & 0 & 3 & 5 & 10 & 20 & 30 & 50 \\
\hline Composite bar results & & & & & & & \\
Avg. water uptake, $3 \mathrm{~h}(\%, \mathrm{n}=3)$ & 5.1 & 7.0 & 8.5 & 10.1 & 11.6 & 13.2 & 16.0 \\
Standard error $(\%)$ & 0.3 & 0.6 & 0.3 & 0.1 & 0.3 & 0.4 & 0.8 \\
\hline $\begin{array}{l}\text { Avg. water uptake, } 24 \mathrm{~h}(\%, \mathrm{n}=3) \\
\text { Standard error }(\%)\end{array}$ & 9.5 & 14.1 & 15.2 & 21.2 & 23.5 & 26.7 & 31.9 \\
\hline
\end{tabular}

TABLE S22.

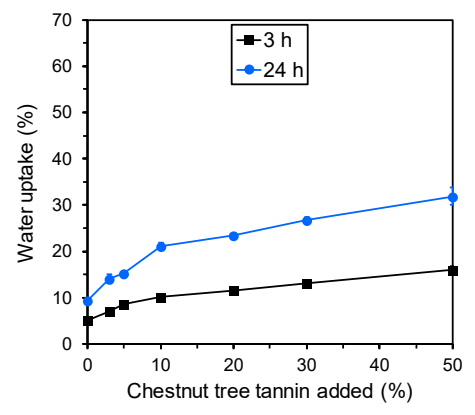

FIGURE S7. 


\section{Results for binder compositions comprising GA291v modified with TC in the presence of $\mathrm{NaOH}$ at pH 9}

The results obtained for binder compositions comprising GA291v modified with TC in the presence of $\mathrm{NaOH}$ at $\mathrm{pH} 9$ are shown in Table S23 and Figure S8.

\begin{tabular}{|c|c|c|c|c|c|c|c|}
\hline Entry & 1 & 2 & 3 & 4 & 5 & 6 & 7 \\
\hline \multicolumn{8}{|l|}{ Binder composition } \\
\hline GA291v & 100 & 100 & 100 & 100 & 100 & 100 & 100 \\
\hline TC (\%-wt. of gelatin) & 0 & 3 & 5 & 10 & 20 & 30 & 50 \\
\hline \multicolumn{8}{|l|}{ Composite bar results } \\
\hline Avg. unaged mechanical strength $(\mathrm{kN}, \mathrm{n}=5)$ & 0.251 & 0.303 & 0.322 & 0.302 & 0.273 & 0.226 & 0.148 \\
\hline Standard error $(\mathrm{kN})$ & 0.013 & 0.017 & 0.012 & 0.015 & 0.015 & 0.006 & 0.009 \\
\hline Binder content ( $\%$-wt of stone shots) & 2.90 & 2.93 & 2.94 & 2.81 & 2.79 & 2.63 & 2.67 \\
\hline Avg. autoclave aged mech. strength $(\mathrm{kN}, \mathrm{n}=5)$ & 0.252 & 0.289 & 0.241 & 0.216 & 0.192 & 0.172 & 0.129 \\
\hline Standard error $(\mathrm{kN})$ & 0.004 & 0.016 & 0.024 & 0.007 & 0.018 & 0.015 & 0.007 \\
\hline Binder content ( $\%$-wt of stone shots) & 2.90 & 2.86 & 2.88 & 2.85 & 2.87 & 2.68 & 2.68 \\
\hline Avg. water bath aged mech. strength $(\mathrm{kN}, \mathrm{n}=5)$ & 0 & 0.309 & 0.312 & 0.292 & 0.258 & 0.200 & 0.109 \\
\hline Standard error $(\mathrm{kN})$ & - & 0.024 & 0.017 & 0.010 & 0.011 & 0.009 & 0.006 \\
\hline Binder content ( $\%$-wt of stone shots) & 0 & 2.76 & 2.80 & 2.79 & 2.70 & 2.56 & 2.45 \\
\hline Avg. water uptake, $3 \mathrm{~h}(\%, \mathrm{n}=3)$ & 5.9 & 7.6 & 8.1 & 10.4 & 13.5 & 14.4 & 16.3 \\
\hline Standard error $(\%)$ & 0.3 & 0.5 & 0.3 & 0.3 & 0.8 & 0.5 & 0.7 \\
\hline Avg. water uptake, $24 \mathrm{~h}(\%, \mathrm{n}=3)$ & 10.3 & 18.3 & 18.6 & 23.1 & 29.7 & 32.2 & 33.3 \\
\hline Standard error $(\%)$ & 0.1 & 1.3 & 0.2 & 0.8 & 1.3 & 0.6 & 0.5 \\
\hline
\end{tabular}

TABLE S23.
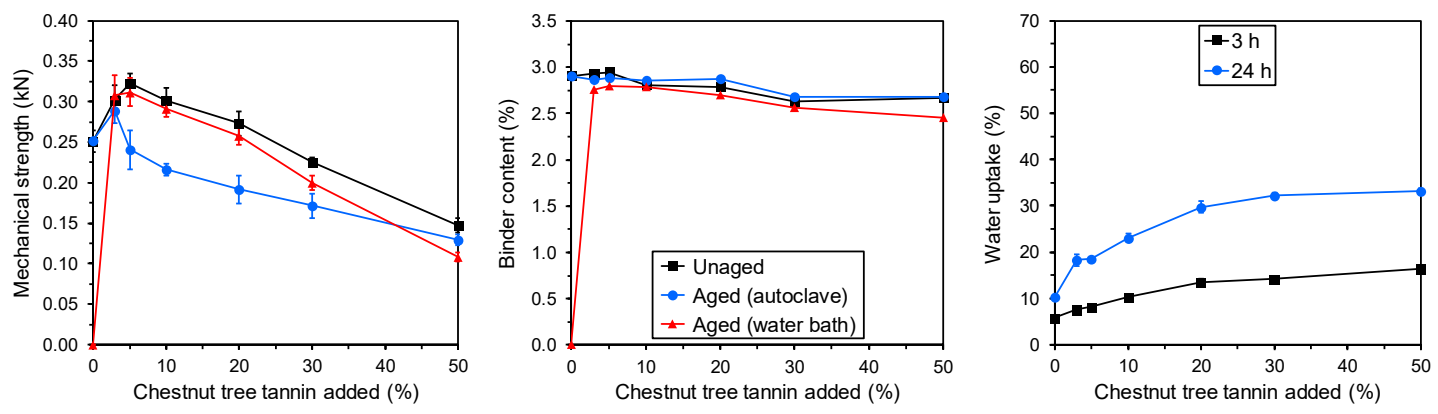

FIGURE S8. 


\section{Results for binder compositions comprising GB122 modified with TC in the presence of $\mathrm{NaOH}$ at pH 9}

The results obtained for binder compositions comprising GB122 modified with TC in the presence of $\mathrm{NaOH}$ at $\mathrm{pH} 9$ are shown in Table S24 and Figure S9.

\begin{tabular}{|c|c|c|c|c|c|c|c|}
\hline Entry & 1 & 2 & 3 & 4 & 5 & 6 & 7 \\
\hline \multicolumn{8}{|l|}{ Binder composition } \\
\hline GB122 & 100 & 100 & 100 & 100 & 100 & 100 & 100 \\
\hline TC (\%-wt. of gelatin) & 0 & 3 & 5 & 10 & 20 & 30 & 50 \\
\hline \multicolumn{8}{|l|}{ Composite bar results } \\
\hline Avg. unaged mechanical strength $(\mathrm{kN}, \mathrm{n}=5)$ & 0.234 & 0.246 & 0.258 & 0.246 & 0.170 & 0.143 & 0.088 \\
\hline Standard error $(\mathrm{kN})$ & 0.018 & 0.006 & 0.013 & 0.016 & 0.012 & 0.012 & 0.009 \\
\hline Binder content ( $\%$-wt of stone shots) & 2.81 & 2.79 & 2.80 & 2.76 & 2.71 & 2.69 & 2.63 \\
\hline Avg. autoclave aged mech. strength $(\mathrm{kN}, \mathrm{n}=5)$ & 0.169 & 0.230 & 0.239 & 0.236 & 0.150 & 0.131 & 0.083 \\
\hline Standard error $(\mathrm{kN})$ & 0.006 & 0.022 & 0.022 & 0.017 & 0.009 & 0.013 & 0.008 \\
\hline Binder content (\%-wt of stone shots) & 2.80 & 2.77 & 2.77 & 2.72 & 2.67 & 2.63 & 2.57 \\
\hline Avg. water bath aged mech. strength $(\mathrm{kN}, \mathrm{n}=5)$ & 0 & 0.139 & 0.154 & 0.140 & 0.134 & 0.091 & 0.057 \\
\hline Standard error $(\mathrm{kN})$ & - & 0.012 & 0.008 & 0.006 & 0.010 & 0.006 & 0.005 \\
\hline Binder content ( $\%$-wt of stone shots) & 0 & 2.21 & 2.35 & 2.47 & 2.48 & 2.41 & 2.22 \\
\hline Avg. water uptake, $3 \mathrm{~h}(\%, \mathrm{n}=3)$ & 24.7 & 24.8 & 24.2 & 26.3 & 28.2 & 26.2 & 29.6 \\
\hline Standard error $(\%)$ & 1.7 & 2.1 & 1.1 & 0.2 & 1.5 & 2.2 & 0.5 \\
\hline Avg. water uptake, $24 \mathrm{~h}(\%, \mathrm{n}=3)$ & 38.1 & 41.9 & 41.1 & 45.5 & 54.7 & 53.2 & 61.0 \\
\hline Standard error $(\%)$ & 1.4 & 2.6 & 1.1 & 0.5 & 1.9 & 3.2 & 2.8 \\
\hline
\end{tabular}

TABLE S24.
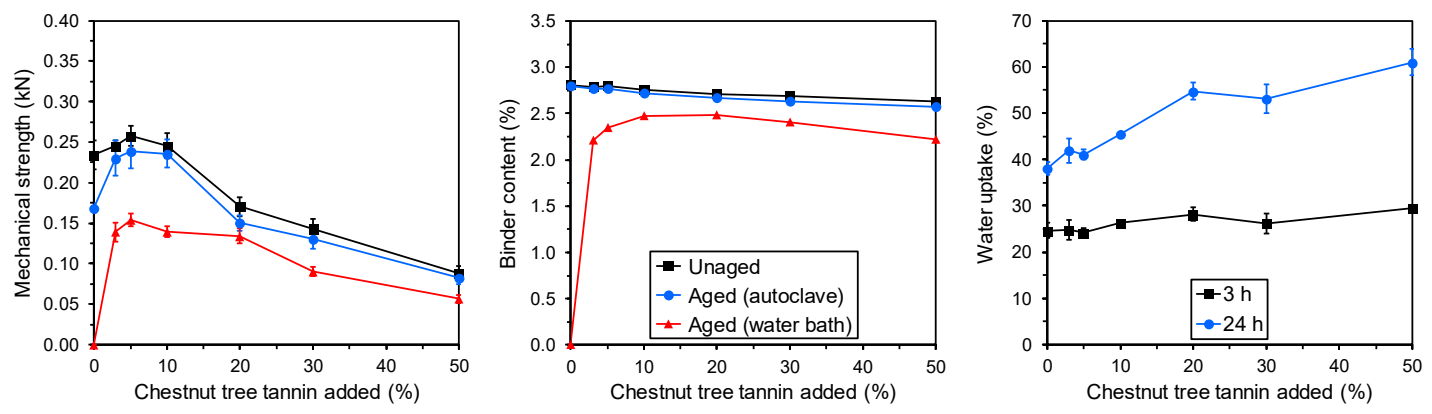

FIGURE S9. 


\section{Results for binder compositions comprising GB267 modified with TC in the presence of $\mathrm{NaOH}$ at pH 9}

The results obtained for binder compositions comprising GB267 modified with TC in the presence of $\mathrm{NaOH}$ at $\mathrm{pH} 9$ are shown in Table S25 and Figure S10.

\begin{tabular}{|c|c|c|c|c|c|c|c|}
\hline Entry & 1 & 2 & 3 & 4 & 5 & 6 & 7 \\
\hline \multicolumn{8}{|l|}{ Binder composition } \\
\hline GB267 & 100 & 100 & 100 & 100 & 100 & 100 & 100 \\
\hline TC (\%-wt. of gelatin) & 0 & 3 & 5 & 10 & 20 & 30 & 50 \\
\hline \multicolumn{8}{|l|}{ Composite bar results } \\
\hline Avg. unaged mechanical strength $(\mathrm{kN}, \mathrm{n}=5)$ & 0.322 & 0.364 & 0.357 & 0.315 & 0.297 & 0.279 & 0.272 \\
\hline Standard error $(\mathrm{kN})$ & 0.014 & 0.08 & 0.015 & 0.019 & 0.012 & 0.011 & 0.017 \\
\hline Binder content ( $\%$-wt of stone shots) & 3.01 & 3.00 & 2.93 & 2.94 & 2.92 & 2.85 & 2.83 \\
\hline Avg. autoclave aged mech. strength $(\mathrm{kN}, \mathrm{n}=5)$ & 0.380 & 0.306 & 0.301 & 0.237 & 0.206 & 0.213 & 0.178 \\
\hline Standard error $(\mathrm{kN})$ & 0.012 & 0.016 & 0.020 & 0.012 & 0.011 & 0.019 & 0.011 \\
\hline Binder content (\%-wt of stone shots) & 2.97 & 2.96 & 2.89 & 2.86 & 2.78 & 2.77 & 2.71 \\
\hline Avg. water bath aged mech. strength $(\mathrm{kN}, \mathrm{n}=5)$ & 0 & 0.192 & 0.212 & 0.201 & 0.151 & 0.161 & 0.112 \\
\hline Standard error $(\mathrm{kN})$ & - & 0.020 & 0.020 & 0.011 & 0.010 & 0.009 & 0.003 \\
\hline Binder content ( $\%$-wt of stone shots) & 0 & 2.55 & 2.74 & 2.80 & 2.72 & 2.68 & 2.48 \\
\hline Avg. water uptake, $3 \mathrm{~h}(\%, \mathrm{n}=3)$ & 16.9 & 17.0 & 17.7 & 17.2 & 17.2 & 17.5 & 21.1 \\
\hline Standard error $(\%)$ & 1.1 & 1.2 & 1.3 & 0.8 & 0.9 & 0.9 & 0.2 \\
\hline Avg. water uptake, $24 \mathrm{~h}(\%, \mathrm{n}=3)$ & 36.1 & 29.1 & 29.0 & 29.4 & 31.7 & 33.0 & 38.4 \\
\hline Standard error $(\%)$ & 1.4 & 1.7 & 0.4 & 1.2 & 0.6 & 1.3 & 1.1 \\
\hline
\end{tabular}

TABLE S25.
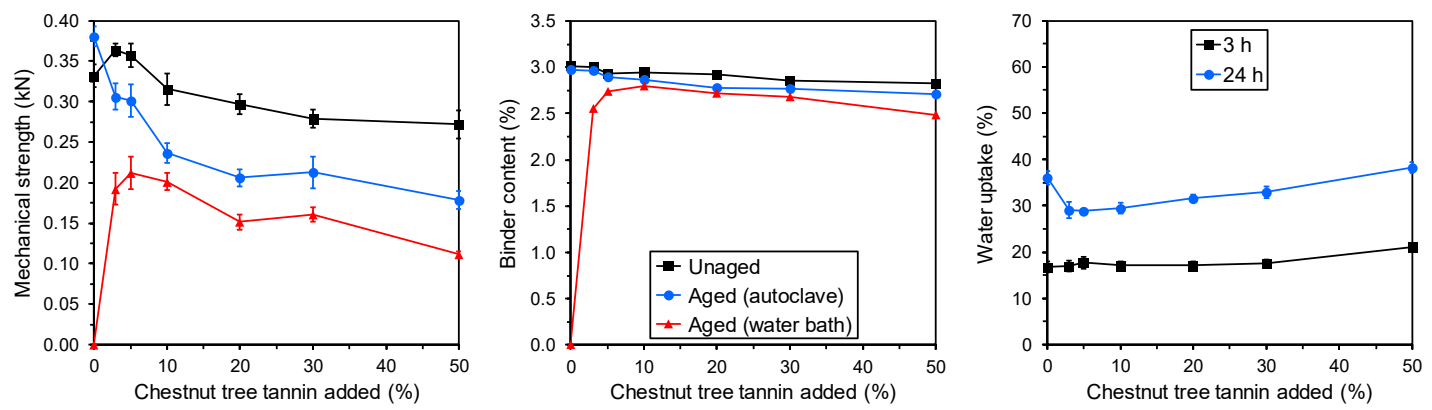

FIGURE S10. 


\section{Results for binder compositions comprising GB278vs modified with TC in the presence of $\mathrm{NaOH}$ at pH 9}

The results obtained for binder compositions comprising GB278vs modified with TC in the presence of $\mathrm{NaOH}$ at $\mathrm{pH} 9$ are shown in Table S26 and Figure S11.

\begin{tabular}{|c|c|c|c|c|c|c|c|}
\hline Entry & 1 & 2 & 3 & 4 & 5 & 6 & 7 \\
\hline \multicolumn{8}{|l|}{ Binder composition } \\
\hline GB278vs & 100 & 100 & 100 & 100 & 100 & 100 & 100 \\
\hline TC (\%-wt. of gelatin) & 0 & 3 & 5 & 10 & 20 & 30 & 50 \\
\hline \multicolumn{8}{|l|}{ Composite bar results } \\
\hline Avg. unaged mechanical strength $(\mathrm{kN}, \mathrm{n}=5)$ & 0.294 & 0.332 & 0.307 & 0.318 & 0.272 & 0.256 & 0.169 \\
\hline Standard error $(\mathrm{kN})$ & 0.010 & 0.022 & 0.022 & 0.014 & 0.016 & 0.008 & 0.012 \\
\hline Binder content ( $\%$-wt of stone shots) & 2.85 & 2.82 & 2.85 & 2.75 & 2.70 & 2.65 & 2.68 \\
\hline Avg. autoclave aged mech. strength $(\mathrm{kN}, \mathrm{n}=5)$ & 0.291 & 0.369 & 0.346 & 0.319 & 0.239 & 0.202 & 0.134 \\
\hline Standard error $(\mathrm{kN})$ & 0.005 & 0.023 & 0.016 & 0.022 & 0.023 & 0.014 & 0.012 \\
\hline Binder content (\%-wt of stone shots) & 2.80 & 2.79 & 2.76 & 2.72 & 2.69 & 2.66 & 2.65 \\
\hline Avg. water bath aged mech. strength $(\mathrm{kN}, \mathrm{n}=5)$ & 0 & 0.301 & 0.302 & 0.257 & 0.213 & 0.197 & 0.129 \\
\hline Standard error $(\mathrm{kN})$ & - & 0.014 & 0.016 & 0.006 & 0.013 & 0.010 & 0.009 \\
\hline Binder content ( $\%$-wt of stone shots) & 0 & 2.71 & 2.69 & 2.72 & 2.60 & 2.59 & 2.43 \\
\hline Avg. water uptake, $3 \mathrm{~h}(\%, \mathrm{n}=3)$ & 23.9 & 17.8 & 13.8 & 15.7 & 16.4 & 15.8 & 17.3 \\
\hline Standard error $(\%)$ & 0.3 & 1.2 & 0.9 & 1.2 & 1.3 & 0.4 & 0.3 \\
\hline Avg. water uptake, $24 \mathrm{~h}(\%, \mathrm{n}=3)$ & 31.6 & 29.6 & 24.0 & 27.9 & 32.0 & 31.9 & 33.7 \\
\hline Standard error $(\%)$ & 2.3 & 0.6 & 0.7 & 0.6 & 2.0 & 0.6 & 0.5 \\
\hline
\end{tabular}

TABLE S26.
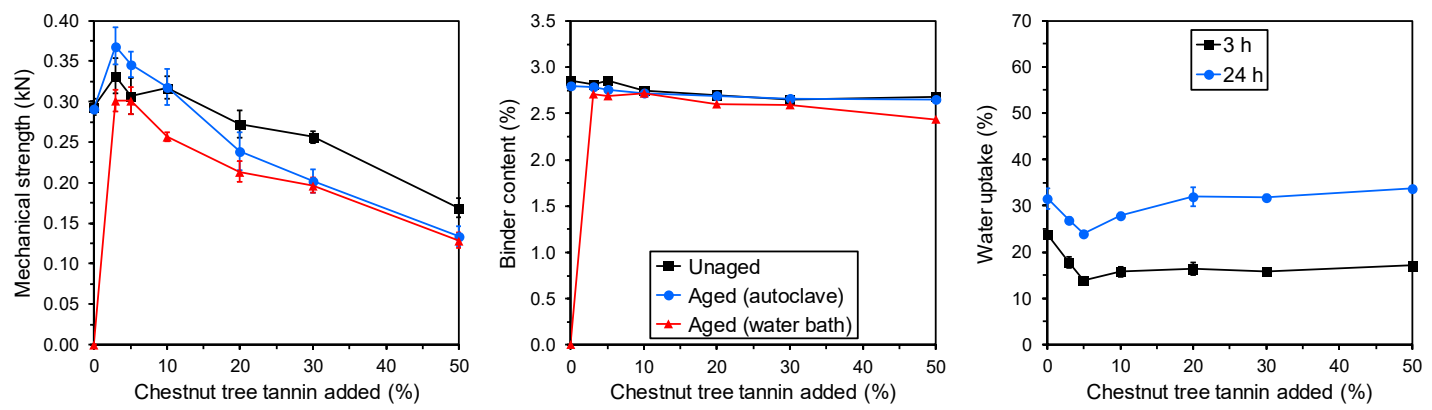

FIGURE S11. 


\section{Results for binder compositions comprising GA120/GA305 90:10 modified with TC in the presence of $\mathrm{NaOH}$ at $\mathrm{pH} 9$}

The results obtained for binder compositions comprising GA120/GA305 90:10 modified with $\mathrm{TC}$ in the presence of $\mathrm{NaOH}$ at $\mathrm{pH} 9$ are shown in the Table $\mathrm{S} 27$ and Figure $\mathrm{S} 12$.

\begin{tabular}{|c|c|c|c|c|c|}
\hline Entry & 1 & 2 & 3 & 4 & 5 \\
\hline \multicolumn{6}{|l|}{ Binder composition } \\
\hline GA120 + GA305 & 100 & 100 & 100 & 100 & 100 \\
\hline GA120 (\%-wt. of gelatin) & 90 & 90 & 90 & 90 & 90 \\
\hline GA305 (\%-wt. of gelatin) & 10 & 10 & 10 & 10 & 10 \\
\hline TC (\%-wt. of gelatin) & 0 & 3 & 5 & 10 & 20 \\
\hline \multicolumn{6}{|l|}{ Composite bar results } \\
\hline Avg. unaged mechanical strength $(\mathrm{kN}, \mathrm{n}=5)$ & 0.229 & 0.258 & 0.248 & 0.235 & 0.210 \\
\hline Standard error $(\mathrm{kN})$ & 0.009 & 0.014 & 0.013 & 0.011 & 0.011 \\
\hline Binder content ( $\%$-wt of stone shots) & 2.78 & 2.80 & 2.77 & 2.77 & 2.75 \\
\hline Avg. autoclave aged mechanical strength $(\mathrm{kN}, \mathrm{n}=5)$ & 0.223 & 0.222 & 0.225 & 0.218 & 0.192 \\
\hline Standard error $(\mathrm{kN})$ & 0.020 & 0.021 & 0.007 & 0.009 & 0.013 \\
\hline Binder content ( $\%$-wt of stone shots) & 2.77 & 2.77 & 2.75 & 2.75 & 2.71 \\
\hline Avg. water bath aged mechanical strength $(\mathrm{kN}, \mathrm{n}=5)$ & 0 & 0.143 & 0.176 & 0.174 & 0.125 \\
\hline Standard error $(\mathrm{kN})$ & - & 0.008 & 0.010 & 0.018 & 0.011 \\
\hline Binder content ( $\%$-wt of stone shots) & 0 & 2.48 & 2.54 & 2.59 & 2.54 \\
\hline Avg. water uptake, $3 \mathrm{~h}(\%, \mathrm{n}=3)$ & 7.8 & 13.7 & 13.3 & 15.6 & 17.4 \\
\hline Standard error $(\%)$ & 0.6 & 0.5 & 0.2 & 1.2 & 0.6 \\
\hline Avg. water uptake, $24 \mathrm{~h}(\%, \mathrm{n}=3)$ & 16.6 & 27.6 & 25.0 & 28.6 & 34.2 \\
\hline Standard error $(\%)$ & 0.8 & 2.3 & 0.4 & 0.8 & 0.8 \\
\hline
\end{tabular}

TABLE S27.
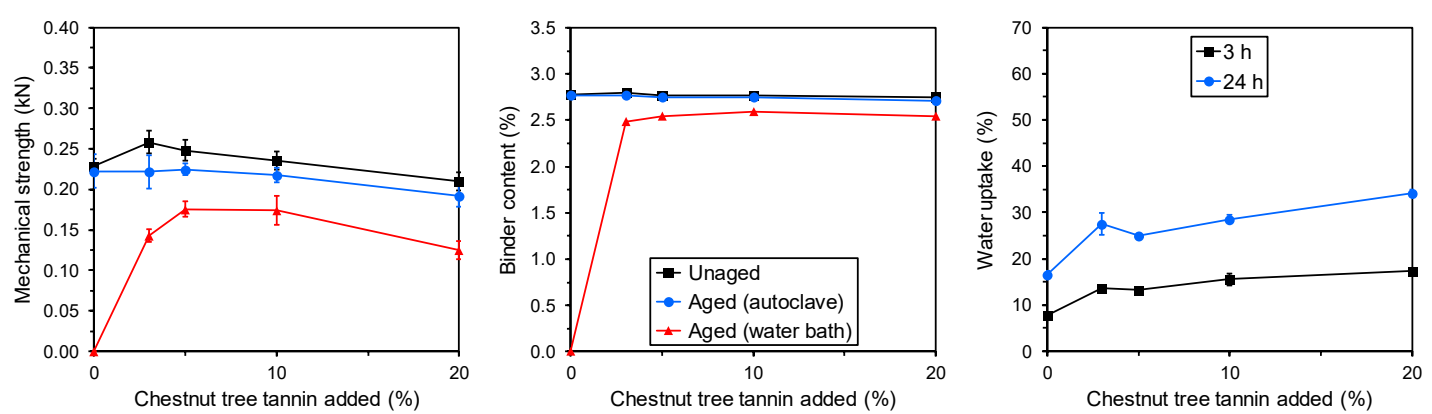

FIGURE S12. 


\section{Results for binder compositions comprising GA120/GB278vs 90:10 modified with TC in the presence of $\mathrm{NaOH}$ at $\mathrm{pH} 9$}

The results obtained for binder compositions comprising GA120/GB278vs 90:10 modified with $\mathrm{TC}$ in the presence of $\mathrm{NaOH}$ at $\mathrm{pH} 9$ are shown in Table S28 and Figure S13.

\begin{tabular}{|c|c|c|c|c|c|}
\hline Entry & 1 & 2 & 3 & 4 & 5 \\
\hline \multicolumn{6}{|l|}{ Binder composition } \\
\hline GA120 + GB278vs & 100 & 100 & 100 & 100 & 100 \\
\hline GA120 (\%-wt. of gelatin) & 90 & 90 & 90 & 90 & 90 \\
\hline GB278vs (\%-wt. of gelatin) & 10 & 10 & 10 & 10 & 10 \\
\hline TC (\%-wt. of gelatin) & 0 & 3 & 5 & 10 & 20 \\
\hline \multicolumn{6}{|l|}{ Composite bar results } \\
\hline Avg. unaged mechanical strength $(\mathrm{kN}, \mathrm{n}=5)$ & 0.200 & 0.222 & 0.225 & 0.196 & 0.175 \\
\hline Standard error $(\mathrm{kN})$ & 0.018 & 0.021 & 0.014 & 0.016 & 0.016 \\
\hline Binder content (\%-wt of stone shots) & 2.76 & 2.78 & 2.77 & 2.74 & 2.74 \\
\hline Avg. autoclave aged mechanical strength $(\mathrm{kN}, \mathrm{n}=5)$ & 0.180 & 0.206 & 0.216 & 0.201 & 0.176 \\
\hline Standard error $(\mathrm{kN})$ & 0.008 & 0.021 & 0.017 & 0.016 & 0.013 \\
\hline Binder content (\%-wt of stone shots) & 2.77 & 2.74 & 2.73 & 2.72 & 2.68 \\
\hline Avg. water bath aged mechanical strength $(\mathrm{kN}, \mathrm{n}=5)$ & 0 & 0.191 & 0.208 & 0.219 & 0.205 \\
\hline Standard error $(\mathrm{kN})$ & - & 0.005 & 0.015 & 0.013 & 0.010 \\
\hline Binder content ( $\%$-wt of stone shots) & 0 & 2.46 & 2.56 & 2.61 & 2.58 \\
\hline Avg. water uptake, $3 \mathrm{~h}(\%, \mathrm{n}=3)$ & 8.4 & 17.3 & 18.2 & 19.0 & 19.6 \\
\hline Standard error $(\%)$ & 0.4 & 1.4 & 1.5 & 1.4 & 1.3 \\
\hline Avg. water uptake, $24 \mathrm{~h}(\%, \mathrm{n}=3)$ & 22.0 & 31.0 & 30.9 & 32.1 & 36.6 \\
\hline Standard error $(\%)$ & 0.8 & 3.2 & 1.2 & 2.3 & 1.3 \\
\hline
\end{tabular}

TABLE S28.
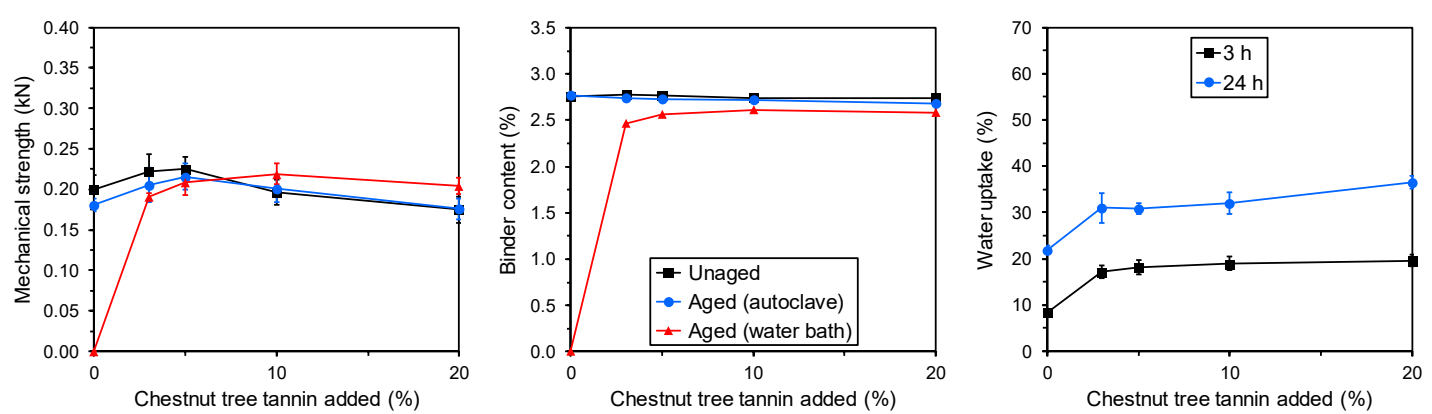

FIGURE S13. 


\section{Results for binder compositions comprising GA120 modified with TA in the presence of $\mathrm{NaOH}$ at pH 9}

The results obtained for binder compositions comprising GA120 modified with TA in the presence of $\mathrm{NaOH}$ at $\mathrm{pH} 9$ are shown in Table S29 and Figure S14.

\begin{tabular}{|c|c|c|c|c|c|c|c|}
\hline Entry & 1 & 2 & 3 & 4 & 5 & 6 & 7 \\
\hline \multicolumn{8}{|l|}{ Binder composition } \\
\hline GA120 & 100 & 100 & 100 & 100 & 100 & 100 & 100 \\
\hline TA (\%-wt. of gelatin) & 0 & 3 & 5 & 10 & 20 & 30 & 50 \\
\hline \multicolumn{8}{|l|}{ Composite bar results } \\
\hline Avg. unaged mechanical strength $(\mathrm{kN}, \mathrm{n}=5)$ & 0.233 & 0.200 & 0.204 & 0.203 & 0.201 & 0.179 & 0.106 \\
\hline Standard error $(\mathrm{kN})$ & 0.017 & 0.008 & 0.007 & 0.013 & 0.018 & 0.004 & 0.003 \\
\hline Binder content ( $\%$-wt of stone shots) & 2.77 & 2.75 & 2.72 & 2.71 & 2.61 & 2.57 & 2.51 \\
\hline Avg. autoclave aged mech. strength $(\mathrm{kN}, \mathrm{n}=5)$ & 0.204 & 0.173 & 0.164 & 0.158 & 0.170 & 0.137 & 0.094 \\
\hline Standard error $(\mathrm{kN})$ & 0.019 & 0.017 & 0.010 & 0.016 & 0.008 & 0.004 & 0.005 \\
\hline Binder content ( $\%$-wt of stone shots) & 2.75 & 2.72 & 2.69 & 2.68 & 2.59 & 2.52 & 2.42 \\
\hline Avg. water bath aged mech. strength $(\mathrm{kN}, \mathrm{n}=5)$ & 0 & 0.122 & 0.131 & 0.112 & 0.091 & 0.053 & 0.012 \\
\hline Standard error $(\mathrm{kN})$ & - & 0.009 & 0.011 & 0.010 & 0.004 & 0.005 & 0.001 \\
\hline Binder content ( $\%$-wt of stone shots) & 0 & 2.13 & 2.15 & 2.16 & 2.05 & 1.78 & 1.07 \\
\hline Avg. water uptake, $3 \mathrm{~h}(\%, \mathrm{n}=3)$ & 5.8 & 13.5 & 15.0 & 18.6 & 17.8 & 27.3 & 42.7 \\
\hline Standard error $(\%)$ & 0.1 & 0.5 & 0.5 & 0.4 & 1.5 & 0.1 & 1.8 \\
\hline Avg. water uptake, $24 \mathrm{~h}(\%, \mathrm{n}=3)$ & 11.2 & 27.4 & 30.0 & 33.4 & 37.5 & 46.0 & 56.5 \\
\hline Standard error $(\%)$ & 0.1 & 0.4 & 1.8 & 1.2 & 0.9 & 1.1 & 0.4 \\
\hline
\end{tabular}

TABLE S29.
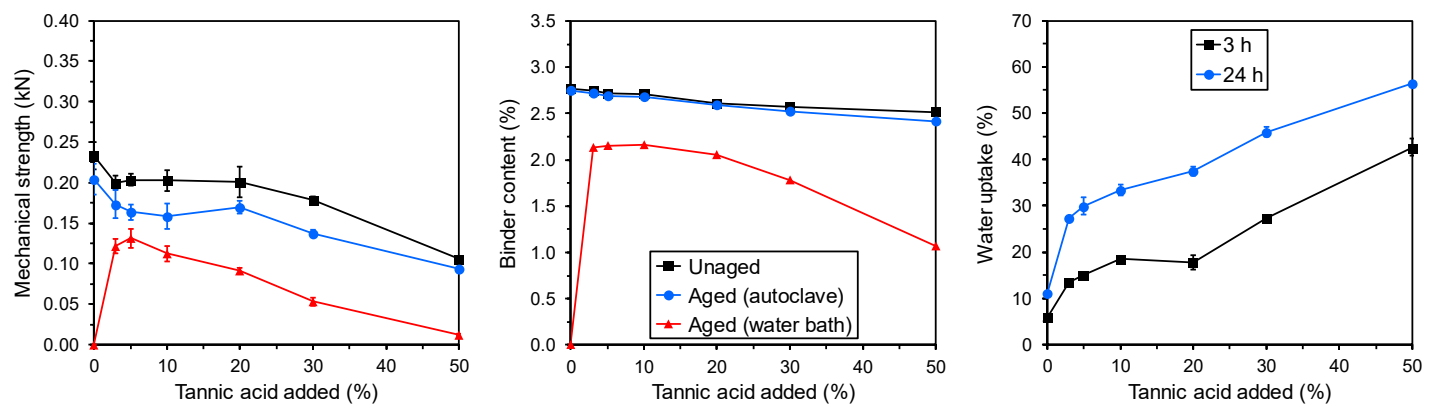

FIGURE S14. 


\section{Results for binder compositions comprising GA120 modified with TG in the presence of $\mathrm{NaOH}$ at pH 9}

The results obtained for binder compositions comprising GA120 modified with TG in the presence of $\mathrm{NaOH}$ at $\mathrm{pH} 9$ are shown in Table S30 and Figure S15.

\begin{tabular}{|c|c|c|c|c|c|c|c|}
\hline Entry & 1 & 2 & 3 & 4 & 5 & 6 & 7 \\
\hline \multicolumn{8}{|l|}{ Binder composition } \\
\hline GA120 & 100 & 100 & 100 & 100 & 100 & 100 & 100 \\
\hline TG (\%-wt. of gelatin) & 0 & 3 & 5 & 10 & 20 & 30 & 50 \\
\hline \multicolumn{8}{|l|}{ Composite bar results } \\
\hline Avg. unaged mechanical strength $(\mathrm{kN}, \mathrm{n}=5)$ & 0.233 & 0.196 & 0.199 & 0.166 & 0.133 & 0.080 & 0.022 \\
\hline Standard error $(\mathrm{kN})$ & 0.017 & 0.009 & 0.013 & 0.016 & 0.006 & 0.004 & 0.001 \\
\hline Binder content ( $\%$-wt of stone shots) & 2.77 & 2.72 & 2.71 & 2.71 & 2.69 & 2.67 & 2.70 \\
\hline Avg. autoclave aged mech. strength $(\mathrm{kN}, \mathrm{n}=5)$ & 0.204 & 0.136 & 0.150 & 0.109 & 0.105 & 0.093 & 0.030 \\
\hline Standard error $(\mathrm{kN})$ & 0.019 & 0.008 & 0.011 & 0.009 & 0.007 & 0.008 & 0.003 \\
\hline Binder content (\%-wt of stone shots) & 2.75 & 2.68 & 2.67 & 2.67 & 2.64 & 2.64 & 2.68 \\
\hline Avg. water bath aged mech. strength $(\mathrm{kN}, \mathrm{n}=5)$ & 0 & 0.089 & 0.015 & 0.102 & 0.071 & 0.051 & 0.010 \\
\hline Standard error $(\mathrm{kN})$ & - & 0.006 & 0.012 & 0.008 & 0.004 & 0.003 & 0.000 \\
\hline Binder content ( $\%$-wt of stone shots) & 0 & 1.84 & 2.07 & 2.13 & 2.32 & 2.32 & 1.80 \\
\hline Avg. water uptake, $3 \mathrm{~h}(\%, \mathrm{n}=3)$ & 5.8 & 10.5 & $12.6^{-}$ & 15.4 & 18.1 & 22.1 & 42.8 \\
\hline Standard error $(\%)$ & 0.1 & 0.5 & 0.4 & 0.7 & 1.5 & 1.7 & 4.3 \\
\hline Avg. water uptake, $24 \mathrm{~h}(\%, \mathrm{n}=3)$ & 11.2 & 22.8 & 23.5 & 30.0 & 29.8 & 34.3 & 50.8 \\
\hline Standard error $(\%)$ & 0.1 & 0.2 & 0.9 & 1.7 & 1.3 & 1.1 & 4.3 \\
\hline
\end{tabular}

TABLE S30.
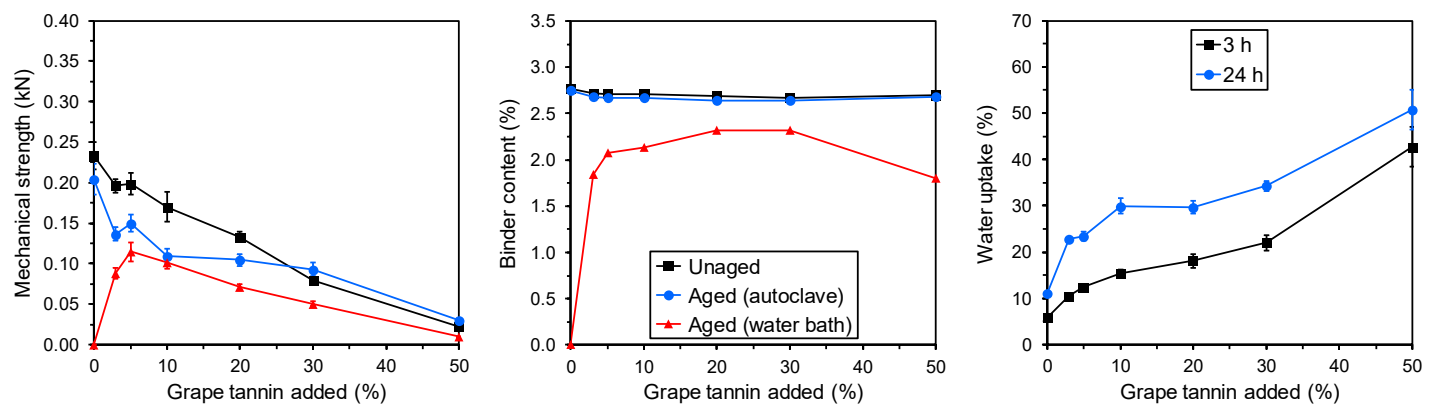

FIGURE S15. 


\section{Results for binder compositions comprising GA120 modified with TO in the presence of $\mathrm{NaOH}$ at pH 9}

The results obtained for binder compositions comprising GA120 modified with TO in the presence of $\mathrm{NaOH}$ at $\mathrm{pH} 9$ are shown in Table S31 and Figure S16.

\begin{tabular}{|c|c|c|c|c|c|c|c|}
\hline Entry & 1 & 2 & 3 & 4 & 5 & 6 & 7 \\
\hline \multicolumn{8}{|l|}{ Binder composition } \\
\hline GA120 & 100 & 100 & 100 & 100 & 100 & 100 & 100 \\
\hline TO (\%-wt. of gelatin) & 0 & 3 & 5 & 10 & 20 & 30 & 50 \\
\hline \multicolumn{8}{|l|}{ Composite bar results } \\
\hline Avg. unaged mechanical strength $(\mathrm{kN}, \mathrm{n}=5)$ & 0.233 & 0.254 & 0.249 & 0.226 & 0.223 & 0.218 & 0.149 \\
\hline Standard error $(\mathrm{kN})$ & 0.017 & 0.008 & 0.010 & 0.018 & 0.005 & 0.015 & 0.013 \\
\hline Binder content ( $\%$-wt of stone shots) & 2.77 & 2.82 & 2.78 & 2.77 & 2.74 & 2.73 & 2.69 \\
\hline Avg. autoclave aged mech. strength $(\mathrm{kN}, \mathrm{n}=5)$ & 0.204 & 0.248 & 0.241 & 0.231 & 0.209 & 0.177 & 0.098 \\
\hline Standard error $(\mathrm{kN})$ & 0.019 & 0.022 & 0.024 & 0.019 & 0.016 & 0.013 & 0.004 \\
\hline Binder content (\%-wt of stone shots) & 2.75 & 2.78 & 2.76 & 2.73 & 2.71 & 2.67 & 2.63 \\
\hline Avg. water bath aged mech. strength $(\mathrm{kN}, \mathrm{n}=5)$ & 0 & 0.185 & 0.211 & 0.180 & 0.184 & 0.131 & 0.064 \\
\hline Standard error $(\mathrm{kN})$ & - & 0.017 & 0.012 & 0.014 & 0.010 & 0.008 & 0.006 \\
\hline Binder content ( $\%$-wt of stone shots) & 0 & 2.52 & 2.54 & 2.54 & 2.51 & 2.44 & 2.18 \\
\hline Avg. water uptake, $3 \mathrm{~h}(\%, \mathrm{n}=3)$ & 5.8 & 15.8 & 14.2 & 15.6 & 13.8 & 15.3 & 31.8 \\
\hline Standard error $(\%)$ & 0.1 & 1.5 & 0.8 & 1.3 & 0.2 & 1.0 & 1.2 \\
\hline Avg. water uptake, $24 \mathrm{~h}(\%, \mathrm{n}=3)$ & 11.2 & 26.7 & 25.8 & 32.1 & 30.2 & 35.2 & 49.3 \\
\hline Standard error $(\%)$ & 0.1 & 2.2 & 0.7 & 0.7 & 1.4 & 2.0 & 2.8 \\
\hline
\end{tabular}

TABLE S31.
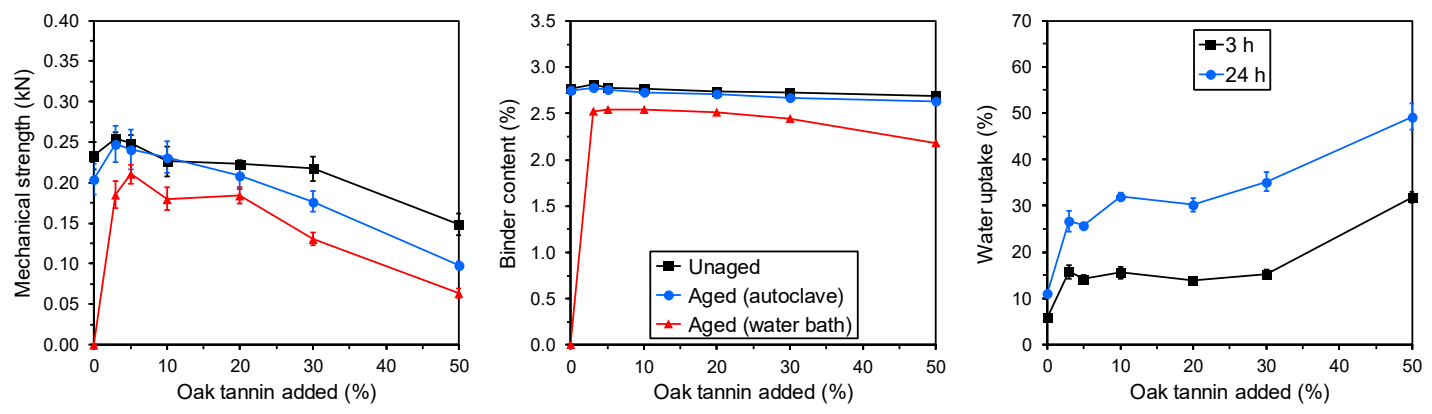

FIGURE S16. 


\section{Results for binder compositions comprising GA120 modified with TQ in the presence of $\mathrm{NaOH}$ at pH 9}

The results obtained for binder compositions comprising GA120 modified with TQ in the presence of $\mathrm{NaOH}$ at $\mathrm{pH} 9$ are shown in Table S32 and Figure S17.

\begin{tabular}{|c|c|c|c|c|c|c|c|}
\hline Entry & 1 & 2 & 3 & 4 & 5 & 6 & 7 \\
\hline \multicolumn{8}{|l|}{ Binder composition } \\
\hline GA120 & 100 & 100 & 100 & 100 & 100 & 100 & 100 \\
\hline TQ (\%-wt. of gelatin) & 0 & 3 & 5 & 10 & 20 & 30 & 50 \\
\hline \multicolumn{8}{|l|}{ Composite bar results } \\
\hline Avg. unaged mechanical strength $(\mathrm{kN}, \mathrm{n}=5)$ & 0.233 & 0.211 & 0.245 & 0.239 & 0.222 & 0.149 & 0.066 \\
\hline Standard error $(\mathrm{kN})$ & 0.017 & 0.015 & 0.020 & 0.020 & 0.011 & 0.004 & 0.006 \\
\hline Binder content ( $\%$-wt of stone shots) & 2.77 & 2.82 & 2.81 & 2.79 & 2.78 & 2.87 & 2.77 \\
\hline Avg. autoclave aged mech. strength $(\mathrm{kN}, \mathrm{n}=5)$ & 0.204 & 0.218 & 0.213 & 0.189 & 0.176 & 0.118 & 0.058 \\
\hline Standard error $(\mathrm{kN})$ & 0.019 & 0.017 & 0.019 & 0.003 & 0.008 & 0.003 & 0.009 \\
\hline Binder content ( $\%$-wt of stone shots) & 2.75 & 2.76 & 2.77 & 2.75 & 2.75 & 2.83 & 2.77 \\
\hline Avg. water bath aged mech. strength $(\mathrm{kN}, \mathrm{n}=5)$ & 0 & 0.146 & 0.178 & $0.177^{-}$ & 0.170 & 0.118 & 0.058 \\
\hline Standard error $(\mathrm{kN})$ & - & 0.007 & 0.012 & 0.010 & 0.030 & 0.010 & 0.005 \\
\hline Binder content ( $\%$-wt of stone shots) & 0 & 2.24 & 2.38 & 2.45 & 2.53 & 2.66 & 2.48 \\
\hline Avg. water uptake, $3 \mathrm{~h}(\%, \mathrm{n}=3)$ & 5.8 & 11.9 & 11.9 & 15.4 & 14.1 & 13.2 & 16.2 \\
\hline Standard error $(\%)$ & 0.1 & 1.1 & 0.5 & 0.2 & 0.9 & 0.3 & 1.1 \\
\hline Avg. water uptake, $24 \mathrm{~h}(\%, \mathrm{n}=3)$ & 11.2 & 30.6 & 28.0 & 27.3 & 27.5 & 27.5 & 31.8 \\
\hline Standard error $(\%)$ & 0.1 & 2.4 & 1.8 & 1.3 & 0.8 & 1.9 & 0.9 \\
\hline
\end{tabular}

TABLE S32.
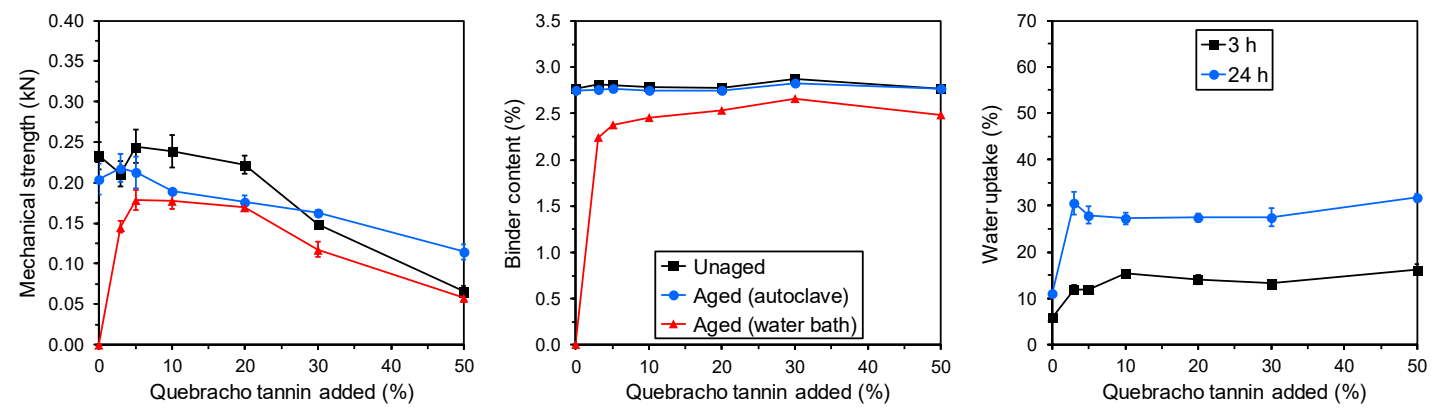

FIGURE S17. 


\section{Results for binder compositions comprising GA120 modified with TC in the presence of KOH at pH 9}

The results obtained for binder compositions comprising GA120 modified with TC in the presence of $\mathrm{KOH}$ at $\mathrm{pH} 9$ are shown in Table S33 and Figure S18.

\begin{tabular}{|c|c|c|c|c|c|}
\hline Entry & 1 & 2 & 3 & 4 & 5 \\
\hline \multicolumn{6}{|l|}{ Binder composition } \\
\hline GA120 & 100 & 100 & 100 & 100 & 100 \\
\hline TC (\%-wt. of gelatin) & 0 & 3 & 5 & 10 & 20 \\
\hline \multicolumn{6}{|l|}{ Composite bar results } \\
\hline Avg. unaged mechanical strength $(\mathrm{kN}, \mathrm{n}=5)$ & 0.194 & 0.249 & 0.242 & 0.234 & 0.227 \\
\hline Standard error $(\mathrm{kN})$ & 0.019 & 0.018 & 0.014 & 0.004 & 0.010 \\
\hline Binder content (\%-wt of stone shots) & 2.89 & 2.90 & 2.79 & 2.83 & 2.78 \\
\hline Avg. autoclave aged mechanical strength $(\mathrm{kN}, \mathrm{n}=5)$ & 0.182 & 0.177 & 0.191 & 0.189 & 0.174 \\
\hline Standard error $(\mathrm{kN})$ & 0.010 & 0.014 & 0.008 & 0.006 & 0.009 \\
\hline Binder content (\%-wt of stone shots) & 2.84 & 2.79 & 2.76 & 2.77 & 2.71 \\
\hline Avg. water bath aged mechanical strength $(\mathrm{kN}, \mathrm{n}=5)$ & 0 & 0.148 & 0.165 & 0.184 & 0.171 \\
\hline Standard error $(\mathrm{kN})$ & - & 0.010 & 0.011 & 0.019 & 0.010 \\
\hline Binder content (\%-wt of stone shots) & 0 & 2.42 & 2.55 & 2.56 & 2.55 \\
\hline Avg. water uptake, $3 \mathrm{~h}(\%, \mathrm{n}=3)$ & 5.9 & 12.0 & 12.3 & 17.0 & 15.3 \\
\hline Standard error (\%) & 0.3 & 1.0 & 1.0 & 0.8 & 0.4 \\
\hline Avg. water uptake, $24 \mathrm{~h}(\%, \mathrm{n}=3)$ & 12.7 & 26.6 & 26.5 & 30.5 & 33.0 \\
\hline Standard error (\%) & 0.3 & 1.8 & 0.9 & 1.2 & 1.0 \\
\hline
\end{tabular}

\section{TABLE S33.}
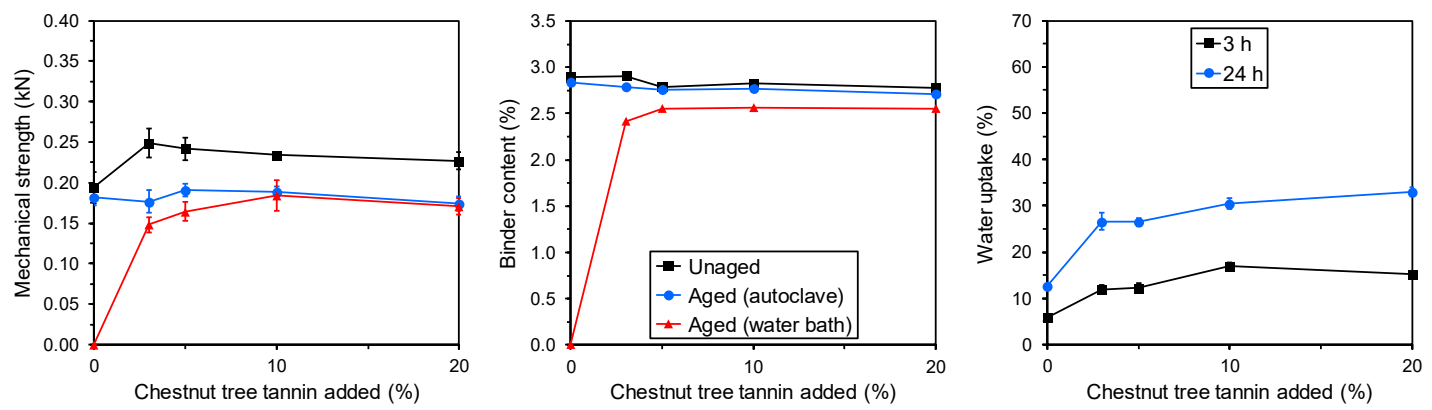

FIGURE S18. 


\section{Results for binder compositions comprising GA120 modified with TC in the presence of LiOH at pH 9}

The results obtained for binder compositions comprising GA120 modified with TC in the presence of $\mathrm{LiOH}$ at $\mathrm{pH} 9$ are shown in Table S34 and Figure S19.

\begin{tabular}{|c|c|c|c|c|c|}
\hline Entry & 1 & 2 & 3 & 4 & 5 \\
\hline \multicolumn{6}{|l|}{ Binder composition } \\
\hline GA120 & 100 & 100 & 100 & 100 & 100 \\
\hline TC (\%-wt. of gelatin) & 0 & 3 & 5 & 10 & 20 \\
\hline \multicolumn{6}{|l|}{ Composite bar results } \\
\hline Avg. unaged mechanical strength $(\mathrm{kN}, \mathrm{n}=5)$ & 0.179 & 0.230 & 0.215 & 0.224 & 0.195 \\
\hline Standard error $(\mathrm{kN})$ & 0.008 & 0.023 & 0.013 & 0.009 & 0.004 \\
\hline Binder content (\%-wt of stone shots) & 2.94 & 2.96 & 2.95 & 2.95 & 2.91 \\
\hline Avg. autoclave aged mechanical strength $(\mathrm{kN}, \mathrm{n}=5)$ & 0.193 & 0.203 & 0.201 & 0.192 & 0.174 \\
\hline Standard error $(\mathrm{kN})$ & 0.010 & 0.012 & 0.020 & 0.006 & 0.008 \\
\hline Binder content (\%-wt of stone shots) & 2.89 & 2.89 & 2.91 & 2.87 & 2.84 \\
\hline Avg. water bath aged mechanical strength $(\mathrm{kN}, \mathrm{n}=5)$ & 0 & 0.175 & 0.187 & 0.178 & 0.161 \\
\hline Standard error $(\mathrm{kN})$ & - & 0.012 & 0.010 & 0.005 & 0.005 \\
\hline Binder content (\%-wt of stone shots) & 0 & 2.61 & 2.69 & 2.70 & 2.67 \\
\hline Avg. water uptake, $3 \mathrm{~h}(\%, \mathrm{n}=3)$ & 5.9 & $10.3^{-}$ & 12.7 & 16.1 & 16.7 \\
\hline Standard error (\%) & 0.1 & 0.4 & 0.7 & 0.7 & 1.4 \\
\hline Avg. water uptake, $24 \mathrm{~h}(\%, \mathrm{n}=3)$ & 13.7 & 22.9 & 25.4 & 30.0 & 35.3 \\
\hline Standard error (\%) & 0.4 & 0.4 & 0.4 & 0.7 & 0.4 \\
\hline
\end{tabular}

\section{TABLE S34}
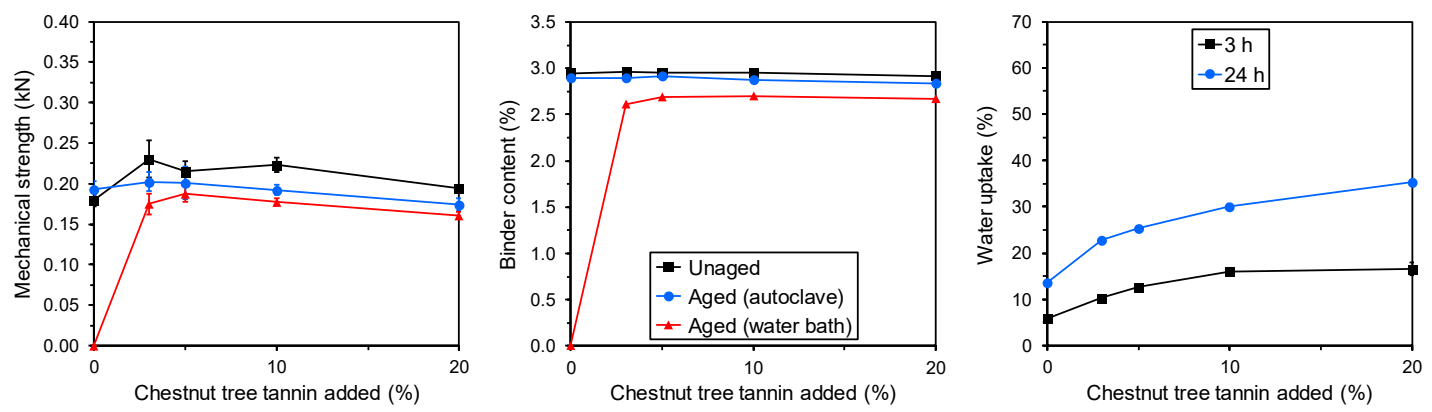

FIGURE S19. 


\section{Results for binder compositions comprising GA120 modified with TC in the presence of $\mathrm{Ca}(\mathrm{OH})_{2}$ at $\mathrm{pH} 9$}

The results obtained for binder compositions comprising GA120 modified with TC in the presence of $\mathrm{Ca}(\mathrm{OH})_{2}$ at $\mathrm{pH} 9$ have been partly disclosed previously. ${ }^{(\mathrm{S} 2)}$ The complete results obtained for binder compositions comprising GA120 modified with TC in the presence of $\mathrm{Ca}(\mathrm{OH})_{2}$ at $\mathrm{pH} 9$ are shown in Table S35 and Figure S20.

\begin{tabular}{|c|c|c|c|c|c|}
\hline Entry & 1 & 2 & 3 & 4 & 5 \\
\hline \multicolumn{6}{|l|}{ Binder composition } \\
\hline GA120 & 100 & 100 & 100 & 100 & 100 \\
\hline TC (\%-wt. of gelatin) & 0 & 3 & 5 & 10 & 20 \\
\hline \multicolumn{6}{|l|}{ Composite bar results } \\
\hline Avg. unaged mechanical strength $(\mathrm{kN}, \mathrm{n}=5)$ & 0.198 & 0.220 & 0.232 & 0.222 & 0.210 \\
\hline Standard error $(\mathrm{kN})$ & 0.020 & 0.018 & 0.011 & 0.022 & 0.012 \\
\hline Binder content ( $\%$-wt of stone shots) & 2.87 & 2.86 & 2.89 & 2.81 & 2.79 \\
\hline Avg. autoclave aged mechanical strength $(\mathrm{kN}, \mathrm{n}=5)$ & 0.191 & 0.200 & 0.191 & 0.156 & 0.151 \\
\hline Standard error $(\mathrm{kN})$ & 0.014 & 0.015 & 0.017 & 0.008 & 0.012 \\
\hline Binder content ( $\%$-wt of stone shots) & 2.83 & 2.80 & 2.82 & 2.73 & 2.71 \\
\hline Avg. water bath aged mechanical strength $(\mathrm{kN}, \mathrm{n}=5)$ & 0 & 0 & 0 & 0.106 & 0.163 \\
\hline Standard error $(\mathrm{kN})$ & - & - & - & 0.007 & 0.013 \\
\hline Binder content ( $\%$-wt of stone shots) & 0 & 0 & 0 & 1.89 & 2.23 \\
\hline Avg. water uptake, $3 \mathrm{~h}(\%, \mathrm{n}=3)$ & 5.5 & 5.8 & 5.3 & 5.4 & 5.0 \\
\hline Standard error $(\%)$ & 0.2 & 0.4 & 0.4 & 0.2 & 0.2 \\
\hline Avg. water uptake, $24 \mathrm{~h}(\%, \mathrm{n}=3)$ & 10.8 & 10.3 & 10.0 & 10.3 & 10.4 \\
\hline Standard error $(\%)$ & 0.3 & 0.5 & 0.5 & 0.2 & 0.4 \\
\hline
\end{tabular}

TABLE S35.
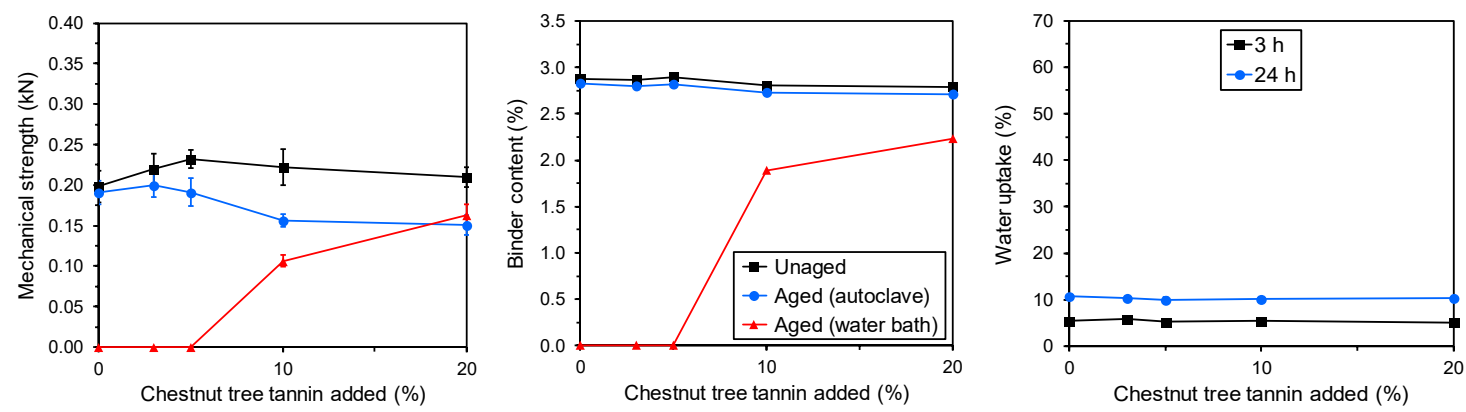

FIGURE S20. 


\section{Results for binder compositions comprising GA120 modified with TC in the presence of $\mathrm{NaOH}$ at pH 7}

The results obtained for binder compositions comprising GA120 modified with TC in the presence of $\mathrm{NaOH}$ at $\mathrm{pH} 7$ are shown in Table S36 and Figure S21.

\begin{tabular}{|c|c|c|c|c|c|}
\hline Entry & 1 & 2 & 3 & 4 & 5 \\
\hline \multicolumn{6}{|l|}{ Binder composition } \\
\hline GA120 & 100 & 100 & 100 & 100 & 100 \\
\hline TC (\%-wt. of gelatin) & 0 & 3 & 5 & 10 & 20 \\
\hline \multicolumn{6}{|l|}{ Composite bar results } \\
\hline Avg. unaged mechanical strength $(\mathrm{kN}, \mathrm{n}=5)$ & 0.216 & 0.259 & 0.249 & 0.245 & 0.202 \\
\hline Standard error $(\mathrm{kN})$ & 0.013 & 0.006 & 0.010 & 0.012 & 0.010 \\
\hline Binder content (\%-wt of stone shots) & 2.80 & 2.79 & 2.81 & 2.76 & 2.74 \\
\hline Avg. autoclave aged mechanical strength $(\mathrm{kN}, \mathrm{n}=5)$ & 0.213 & 0.227 & 0.252 & 0.224 & 0.179 \\
\hline Standard error $(\mathrm{kN})$ & 0.011 & 0.011 & 0.016 & 0.013 & 0.016 \\
\hline Binder content (\%-wt of stone shots) & 2.79 & 2.79 & 2.77 & 2.72 & 2.70 \\
\hline Avg. water bath aged mechanical strength $(\mathrm{kN}, \mathrm{n}=5)$ & 0 & 0.064 & 0.091 & $0.095^{-}$ & 0.066 \\
\hline Standard error $(\mathrm{kN})$ & - & 0.011 & 0.013 & 0.005 & 0.010 \\
\hline Binder content (\%-wt of stone shots) & 0 & 1.36 & 1.83 & 1.94 & 2.06 \\
\hline Avg. water uptake, $3 \mathrm{~h}(\%, \mathrm{n}=3)$ & - & 6.1 & $7.7^{-}$ & 10.9 & 14.9 \\
\hline Standard error (\%) & - & 0.2 & 0.7 & 0.6 & 0.7 \\
\hline Avg. water uptake, $24 \mathrm{~h}(\%, \mathrm{n}=3)$ & - & 18.0 & 20.1 & 26.1 & 30.6 \\
\hline Standard error (\%) & - & 1.4 & 2.0 & 1.2 & 0.6 \\
\hline
\end{tabular}

\section{TABLE S36.}
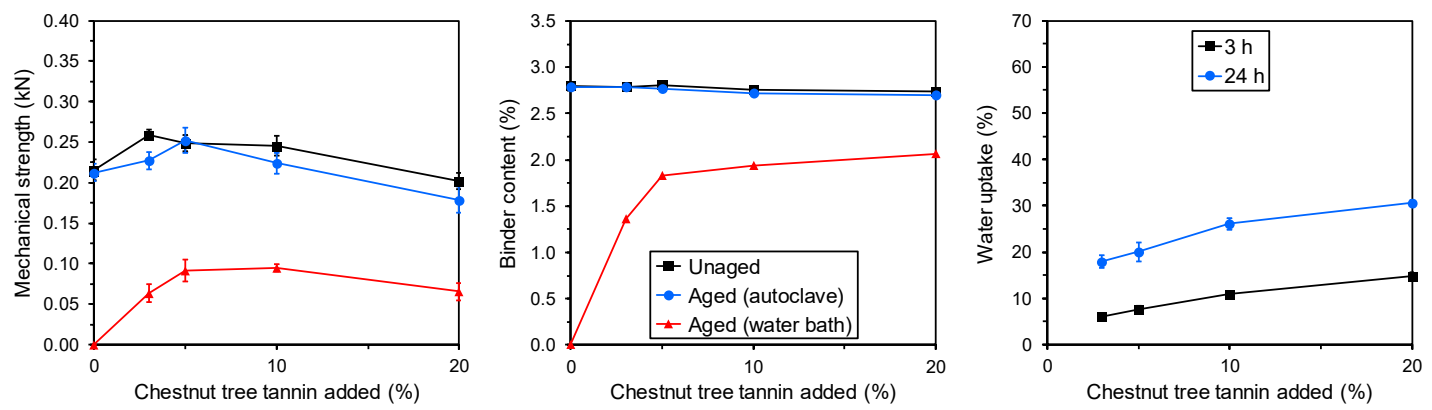

FIGURE S21. 


\section{Results for binder compositions comprising GA120 modified with TC in the presence of $\mathrm{NaOH}$ at pH 8}

The results obtained for binder compositions comprising GA120 modified with TC in the presence of $\mathrm{NaOH}$ at $\mathrm{pH} 8$ are shown in Table S37 and Figure S22.

\begin{tabular}{|c|c|c|c|c|c|}
\hline Entry & 1 & 2 & 3 & 4 & 5 \\
\hline \multicolumn{6}{|l|}{ Binder composition } \\
\hline GA120 & 100 & 100 & 100 & 100 & 100 \\
\hline TC (\%-wt. of gelatin) & 0 & 3 & 5 & 10 & 20 \\
\hline \multicolumn{6}{|l|}{ Composite bar results } \\
\hline Avg. unaged mechanical strength $(\mathrm{kN}, \mathrm{n}=5)$ & 0.236 & 0.221 & 0.264 & 0.271 & 0.229 \\
\hline Standard error $(\mathrm{kN})$ & 0.025 & 0.022 & 0.014 & 0.013 & 0.008 \\
\hline Binder content (\%-wt of stone shots) & 2.84 & 2.86 & 2.80 & 2.80 & 2.73 \\
\hline Avg. autoclave aged mechanical strength $(\mathrm{kN}, \mathrm{n}=5)$ & 0.227 & 0.203 & 0.231 & 0.242 & 0.220 \\
\hline Standard error $(\mathrm{kN})$ & 0.024 & 0.016 & 0.011 & 0.014 & 0.004 \\
\hline Binder content (\%-wt of stone shots) & 2.79 & 2.78 & 2.75 & 2.75 & 2.71 \\
\hline Avg. water bath aged mechanical strength $(\mathrm{kN}, \mathrm{n}=5)$ & 0 & 0.093 & 0.145 & $0.166^{\circ}$ & 0.140 \\
\hline Standard error $(\mathrm{kN})$ & - & 0.015 & 0.010 & 0.011 & 0.013 \\
\hline Binder content (\%-wt of stone shots) & 0 & 2.12 & 2.33 & 2.43 & 2.43 \\
\hline Avg. water uptake, $3 \mathrm{~h}(\%, \mathrm{n}=3)$ & 6.2 & 10.5 & 10.9 & 13.0 & 17.1 \\
\hline Standard error (\%) & 0.2 & 0.4 & 0.6 & 1.3 & 1.0 \\
\hline Avg. water uptake, $24 \mathrm{~h}(\%, \mathrm{n}=3)$ & 12.4 & 24.5 & 25.2 & 27.7 & 34.3 \\
\hline Standard error (\%) & 0.1 & 2.1 & 0.6 & 0.9 & 2.5 \\
\hline
\end{tabular}

\section{TABLE S37.}
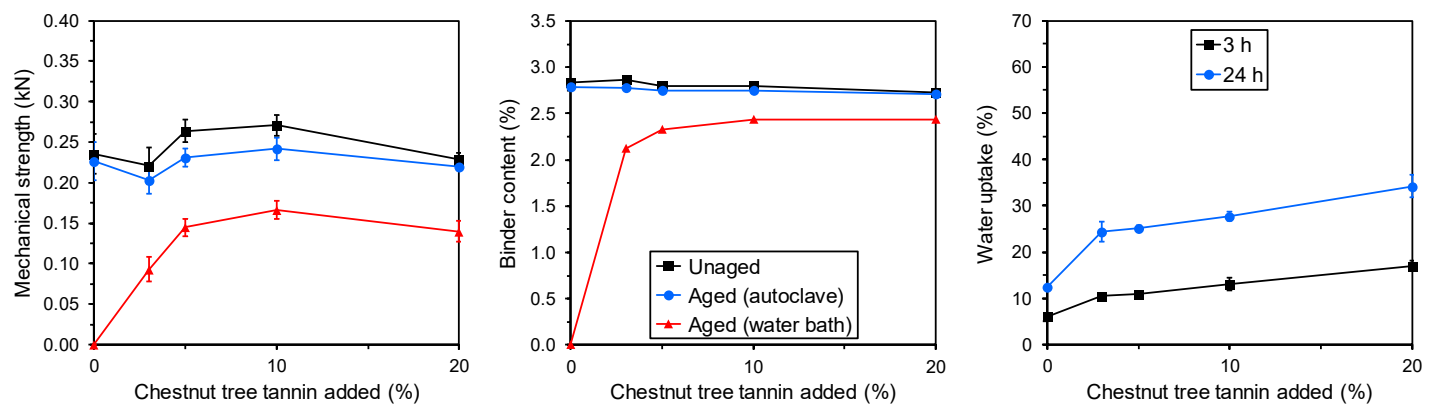

FIGURE S22. 


\section{Results for binder compositions comprising GA120 modified with TC in the presence of $\mathrm{NaOH}$ at pH 11}

The results obtained for binder compositions comprising GA120 modified with TC in the presence of $\mathrm{NaOH}$ at $\mathrm{pH} 11$ are shown in Table S38 and Figure S23.

\begin{tabular}{|c|c|c|c|c|c|}
\hline Entry & 1 & 2 & 3 & 4 & 5 \\
\hline \multicolumn{6}{|l|}{ Binder composition } \\
\hline GA120 & 100 & 100 & 100 & 100 & 100 \\
\hline TC (\%-wt. of gelatin) & 0 & 3 & 5 & 10 & 20 \\
\hline \multicolumn{6}{|l|}{ Composite bar results } \\
\hline Avg. unaged mechanical strength $(\mathrm{kN}, \mathrm{n}=5)$ & 0.130 & 0.180 & 0.177 & 0.192 & 0.177 \\
\hline Standard error $(\mathrm{kN})$ & 0.004 & 0.005 & 0.014 & 0.018 & 0.012 \\
\hline Binder content (\%-wt of stone shots) & 2.84 & 2.84 & 2.82 & 2.76 & 2.69 \\
\hline Avg. autoclave aged mechanical strength $(\mathrm{kN}, \mathrm{n}=5)$ & 0.071 & 0.116 & 0.128 & 0.151 & 0.123 \\
\hline Standard error $(\mathrm{kN})$ & 0.006 & 0.011 & 0.011 & 0.014 & 0.009 \\
\hline Binder content (\%-wt of stone shots) & 2.75 & 2.73 & 2.70 & 2.67 & 2.58 \\
\hline Avg. water bath aged mechanical strength $(\mathrm{kN}, \mathrm{n}=5)$ & 0 & 0.149 & 0.177 & $0.185^{-}$ & 0.136 \\
\hline Standard error $(\mathrm{kN})$ & - & 0.008 & 0.017 & 0.004 & 0.007 \\
\hline Binder content (\%-wt of stone shots) & 0 & 2.40 & 2.54 & 2.57 & 2.46 \\
\hline Avg. water uptake, $3 \mathrm{~h}(\%, \mathrm{n}=3)$ & 18.9 & $18.5^{-}$ & 15.3 & 13.4 & $16.7^{-1}$ \\
\hline Standard error (\%) & 0.6 & 0.7 & 0.3 & 0.2 & 0.7 \\
\hline Avg. water uptake, $24 \mathrm{~h}(\%, \mathrm{n}=3)$ & 33.7 & 34.1 & 30.5 & 30.0 & 43.9 \\
\hline Standard error (\%) & 1.4 & 1.4 & 0.3 & 1.5 & 0.5 \\
\hline
\end{tabular}

\section{TABLE S38.}
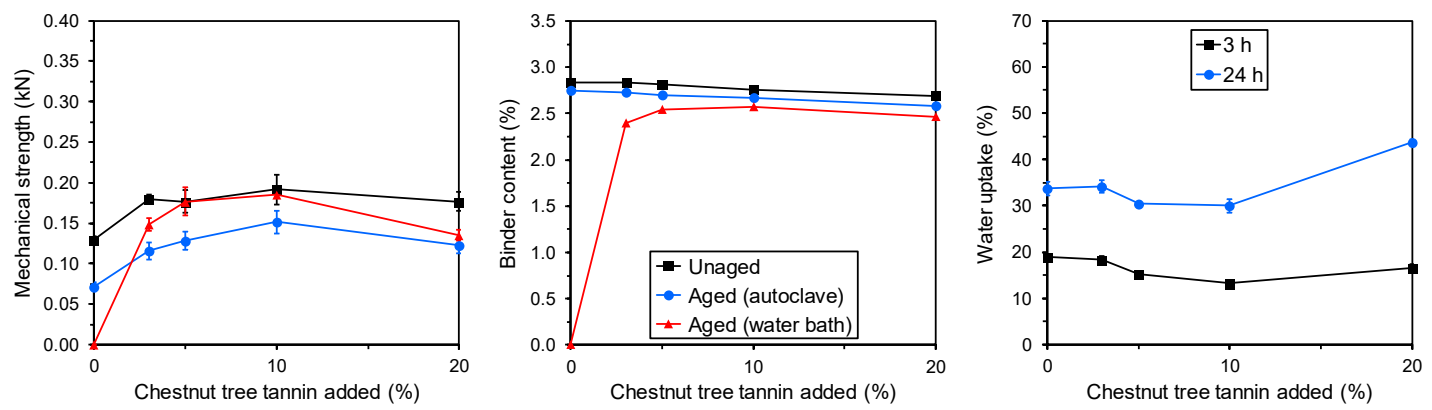

FIGURE S23. 


\section{REFERENCES}

(S1) Hjelmgaard, T.; Thorsen, P. A.; Bøtner, J. A.; Kaurin, J.; Schmücker, C. M.; Nærum, L. Towards greener stone shot and stone wool materials: binder systems based on gelatine modified with tannin or transglutaminase. Green. Chem. 2018, 20, 4102-4111.

${ }^{(\mathrm{S} 2)}$ Hjelmgaard, T. Mineral wool binder; WO2021032645A1, 2021. 